NBER WORKING PAPER SERIES

\title{
CONSUMPTION COMMITMENTS AND PREFERENCES FOR RISK
}

\author{
Andrew Postlewaite \\ Larry Samuelson \\ Dan Silverman \\ Working Paper 10527 \\ http://www.nber.org/papers/w10527
}

\section{NATIONAL BUREAU OF ECONOMIC RESEARCH 1050 Massachusetts Avenue Cambridge, MA 02138}

May 2004

We thank Andy Abel and Jesus Fernandez-Villaverde for helpful conversations, and thank the National Science Foundation for financial support. Correspondence should be sent to Andrew Postlewaite (apostlew@econ.sas.upenn.edu). The views expressed herein are those of the author(s) and not necessarily those of the National Bureau of Economic Research.

(C)2004 by Andrew Postlewaite, Larry Samuelson, and Dan Silverman. All rights reserved. Short sections of text, not to exceed two paragraphs, may be quoted without explicit permission provided that full credit, including $(\mathrm{C}$ notice, is given to the source. 
Consumption Commitments and Preferences for Risk Andrew Postlewaite, Larry Samuelson, and Dan Silverman NBER Working Paper No. 10527

May 2004

JEL No. D21, D31, D81, J34

\section{ABSTRACT}

We examine an economy in which the cost of consuming some goods can be reduced by making commitments to consumption levels independent of the state. For example, it is cheaper to produce housing services via owner-occupied than rented housing, but the transactions costs associated with the former prompt relatively inflexible housing consumption paths. We show that consumption commitments can cause risk-neutral consumers to care about risk, creating incentives to both insure risks and bunch uninsured risks together. For example, workers may prefer to avoid wage risk while bearing an unemployment risk that is concentrated in as few states as possible.

Andrew Postlewaite

Department of Economics

University of Pennsylvania

3718 Locust Walk

Philadelphia, PA 19104-6297

apostlew@econ.sas.upenn.edu

Larry Samuelson

Department of Economics

University of Wisconsin

1180 Observatory Drive

Madison, WI 53706-1393

larrysam@ssc.wisc.edu

Dan Silverman

Department of Economics

University of Wisconsin

1180 Observatory Drive

Madison, WI 53706-1393

dansilv@umich.edu 


\section{Consumption Commitments and Preferences for Risk}

\section{Introduction}

Purchasing a house typically commits one to a mortgage. Negative income shocks can then have serious financial consequences, perhaps even inducing foreclosure. The alternative of renting provides some insulation from income shocks: failing to make the rent may force one to move, but with substantially lower transactions costs and without the risk of a capital loss. One could achieve even more flexibility by living in hotels, adjusting the quality as needed in response to income fluctuations. The salient point is that an individual who purchases housing, or makes any other purchase involving future financial obligations, is likely to have a different attitude toward income risk than one who chooses more flexible arrangements. Analogous effects can arise even without explicit future financial obligations. The expected utility from the use of a vacation home may be jeopardized by negative income shocks, even if there are no further payments to make and the home itself is not at risk. Having a child is similar to committing to a long-term mortgage, but without the default option.

We refer to choices that give rise to rigidities in consumption as consumption commitments. This paper suggests an alternative to the standard ways of thinking about consumption and risk, centering on incentives for consumers to make consumption commitments.

Individuals whose consumption commitments make them more vulnerable to negative income shocks are not necessarily foolish; there are benefits to making these choices. Purchasing a house typically gives greater benefit per dollar spent than does renting an apartment. ${ }^{1}$ Hotels are yet more expensive than apartments. Owning a car is cheaper than renting one, and owning a vacation home near a ski resort can be cheaper than regularly renting. The rental market for children is thin, if it exists at all, with a long-term commitment being the norm.

By themselves, consumption commitments simply point to one more reason why people might prefer less risky income streams. What is important for this paper is that the degree to which an individual is risk averse is endogenous: the vulnerability to future income shocks is a consequence of

\footnotetext{
${ }^{1}$ Not only are there tax benefits associated with home ownership, but purchasing allows one to make idiosyncratic capital improvements that increase the utility of the housing, while renting typically entails a premium because of moral hazard concerns.
} 
his or her consumption decisions. As a result, there are utility gains to individuals from coordinating their consumption and labor market decisions, matching those times that their consumption would be especially vulnerable to income fluctuations with the times that their income is secure. ${ }^{2}$

This coordination can induce "economies of scale" in risk bearing. Once an individual whose income is relatively risky has chosen not to commit to consumption expenditures, the welfare cost of bearing additional risk may be relatively low. An individual faced with a given amount of lifetime income uncertainty then may rationally choose to concentrate as much risk as possible into his or her early years, accommodating the consequent insecure income stream by remaining single, renting an apartment, and buying a cheap used car. If laid off, the individual moves back to her parents' home to await recall while watching daytime television. The flip side of this concentrated employment income risk in early years is a relatively secure income in later years that permits the individual to enjoy the benefits of consumption commitments.

Section 2 presents some evidence consistent with the idea that individuals with less secure incomes are less likely to make consumption commitments. Section 3 presents a simple model of consumption commitments. Section 4 examines the resulting endogeneity of risk aversion. An individual who would be risk neutral in the absence of consumption commitments may be effectively risk averse once such commitments are made, and may face economies of scale in bearing risk.

Section 5 puts these ideas to work, examining the implications of consumption commitments for optimal labor contracts. Wages typically remain relatively rigid, even as firms endure shocks that force them to dismiss workers. An adverse productivity or demand shock to a firm presumably decreases the marginal revenue product of its labor. Why doesn't the firm respond by reducing wages? We suggest that consumption commitments provide part of the answer. The risk aversion induced by inflexible consumption plans induces workers to prefer relatively smooth wage profiles. At the

\footnotetext{
${ }^{2}$ There are several papers that make a similar point. Ellingsen and Holden ([10]) analyze a model in which workers make purchases of durable goods based on expectations about future wages. When those expectations are high, workers will make large purchases, and will resist lower wages more than they would had they had more pessimistic expectations (and consequently purchased fewer durables). In a related paper $([11])$, the authors analyze a model in which worker indebtedness worsens their bargaining position vis a vis employers. In work independent of the current paper, Chetty ([7]) and Chetty and Szeidl ([8]) investigate the connection between consumption commitments and risk attitudes. Chetty demonstrates empirically the importance of commitments in estimating risk aversion, while Chetty and Szeidl show that home ownership affects portfolio composition.
} 
same time, if workers must endure some risk, then the induced economies of scale in risk bearing can prompt them to prefer the risk be concentrated in the form of layoffs.

Section 6 argues that the possibility of consumption commitments may naturally give rise to multiple equilibria. In one equilibrium, individuals concentrate their risk so that they are subject to high risk when young and low risk when older, allowing consumption commitments in the latter case. In another, employment contracts do not concentrate risk and workers avoid consumption commitments. If there are economies of scale in providing consumption commitments, such as owner-occupied housing requiring a sufficiently large mortgage market to allow risk-pooling, then no single firm or individual can break out of this latter equilibrium.

We discuss the results and the related literature in Section 7.

\section{Consumption Commitments}

We begin with some evidence suggestive of a link between the security of one's income stream, captured by the risk of unemployment, and the propensity to make consumption commitments, captured by home ownership. Figure 1 presents the average civilian unemployment rate for the years 1990 to 2000 by age group (measured on the scale on the left), and average home ownership rate for the same period (measured on the right). ${ }^{3}$ The average unemployment rate over this period declines with age, from just under $13 \%$ for the under 25 group to about $3.5 \%$ for the 55 and over group. Home ownership increases from $17 \%$ to $79 \%$ for these two groups respectively.

It is no surprise that those facing higher unemployment rates are less likely to buy houses - they presumably have lower expected incomes. Our emphasis on the potential costs of commitments suggests that in addition to the importance of income levels, income volatility should deter consumption commitments. Figure 2 shows the variance of unemployment rates by age (shown on the left axis) along with home ownership rates. The lower incidence of home ownership among the young is associated with more variable as well as higher unemployment rates (and hence, presumably, incomes).

At the aggregate level, and across age groups, there is thus a relationship between employment, employment certainty, and home ownership. How-

\footnotetext{
${ }^{3}$ Unemployment data is from the Bureau of Labor Statistics, and the home ownership rates are from the HUD website, taken from the Census Bureau. In order to make the age groups the same the group "Under 25" is the average of the numbers for the two groups "16 to 19" and "21 to 24 " years in the BLS data, and the group "25 to 34 " is the average of the two groups " 25 to 29 " and " 30 to 34 " in the HUD data.
} 
Figure 1: Unemployment rates and home ownership rates by age

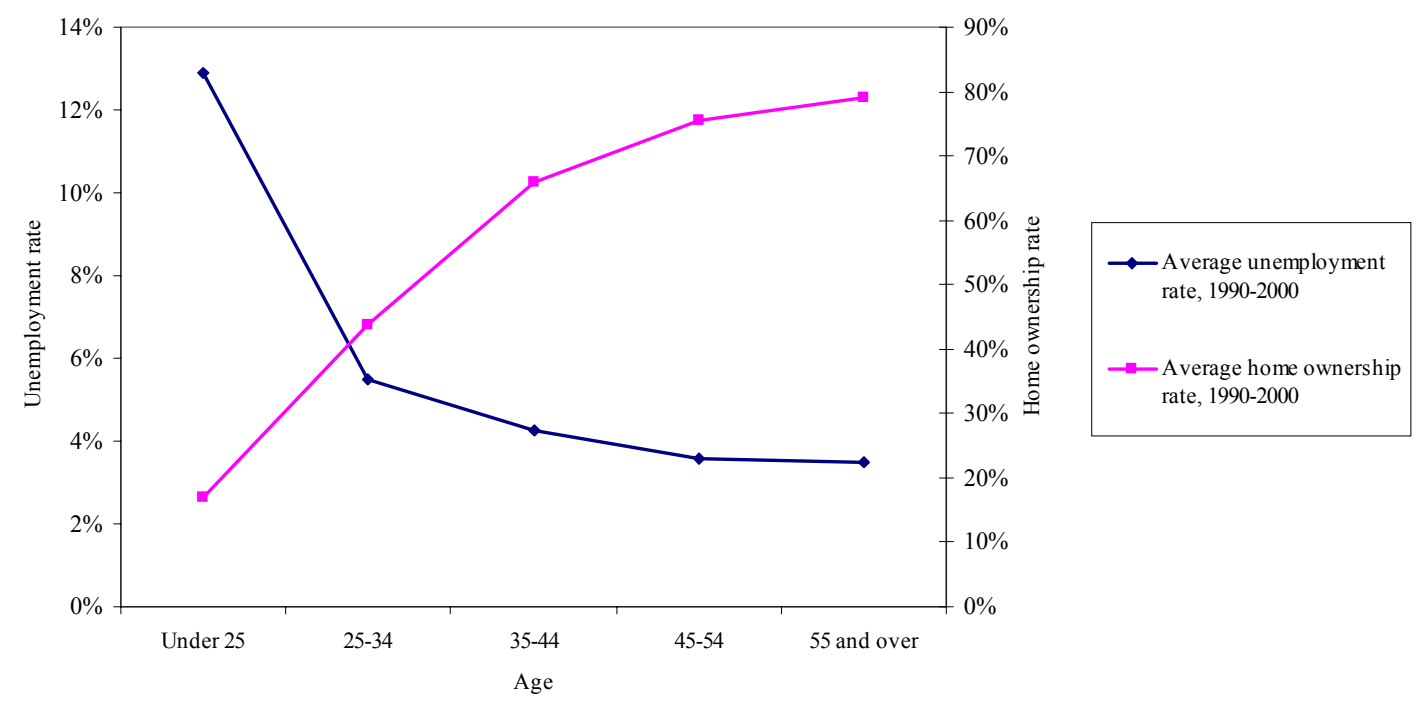

ever, there are many reasons why employment and home ownership patterns might systematically covary across ages, without suggesting any particular link between the two. The Panel Survey of Income Dynamics (PSID) includes information on income volatility and home ownership, allowing us to come closer to our target with a disaggregated analysis that controls for age. Restricting attention to white males ages 30-62 in 1993 with at least three years of income observations, we measure both the degree of income volatility $^{4}$ and the average income of each individual. ${ }^{5}$ Figure 3 presents the results of a probit estimating the probability of home ownership conditional on income volatility, average and current income, number of income

\footnotetext{
${ }^{4}$ Income volatility is represented by the deviations from one-year-ahead expectations of constant income growth. Specifically, if we let $\Delta y_{t i}$ denote individual $i$ 's growth in real income between periods $t$ and $t-1$, our measure of income volatility is given by

$$
V_{i}=\sqrt{\frac{1}{T_{i}-2} \sum_{t=3}^{T_{i}}\left[\Delta y_{t i}-\Delta y_{t i-1}\right]^{2}}
$$

where $T_{i}$ is the number of income observations for individual $i$. Several alternative measures of volatility yielded similar results.

${ }^{5}$ The sample is on average 43 years old in 1993, and we observe an average of 18 years of past income for each respondent.
} 
Figure 2: Variance in unemployment rates and home ownership rates by age

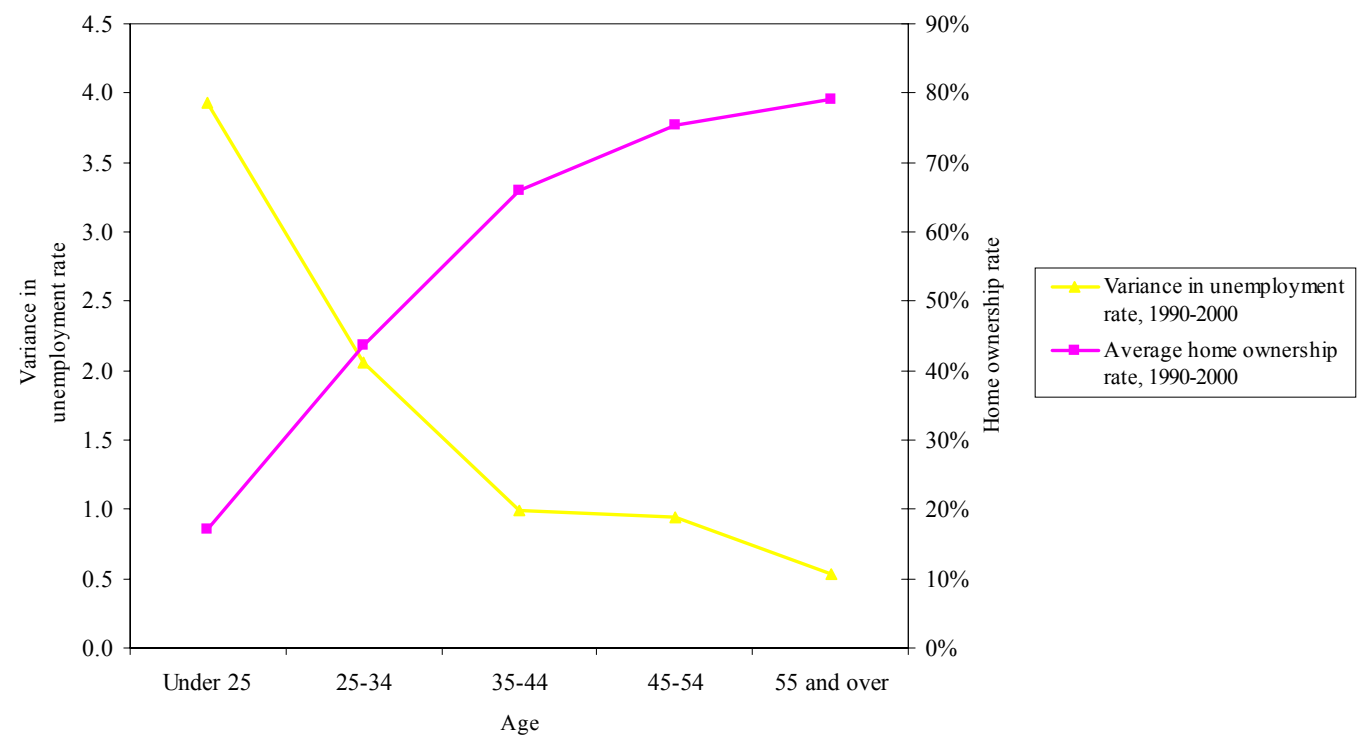

observations, and demographics. This figure shows the change in the predicted probability of home ownership associated with varying levels of income volatility and average income, for an otherwise average respondent. Conditional on age, years of schooling, current and average income, and other demographic variables, increased income volatility is associated with significantly lower probabilities of home ownership. Starting from mean levels of all the variables, a standard deviation increase in conditional income volatility is associated with a $5.8 \%$ decrease in the probability of home ownership. This change should be compared with a similar increase in the level of average income, which is associated with a $17.4 \%$ increase in the probability of home ownership. Roughly speaking, changes in income volatility, conditional on average and current income, are associated with changes in the probability of home ownership on the same order of magnitude as those associated with changes in the level of income.

Though the purchase of a house is one of the most obvious consumption commitments that many families make, we stress that the commitment concept goes well beyond home ownership. For example, the decision to have children entails substantial future expenditures. We can use the PSID to examine the relationship between income volatility and the timing of the 
Figure 3: Predicted probability of home ownership, by income volatility and average income, average white male age 30-62 in the PSID

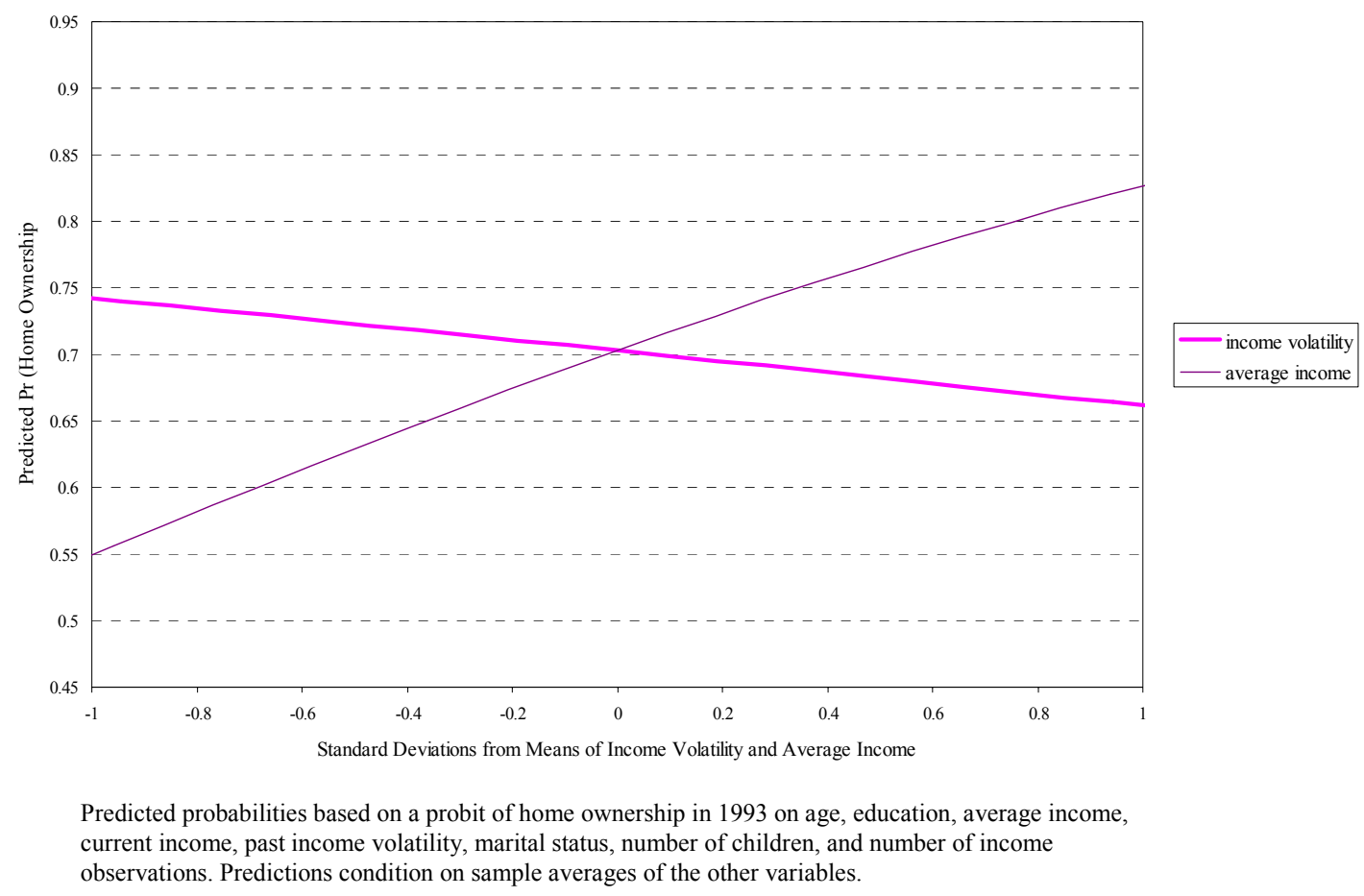

decision to start a family. We again restrict attention to white males ages 30-62 in 1993 with at least three years of income observations, this time restricting attention to those who have fathered at least one child. We find that, conditional on age, years of schooling, current and average income, years in the sample, number of income observations, and demographic variables including the number of children in 1993, increased income volatility is associated with small but statistically significant delays in the decision to start a family. Figure 4 presents the change in the predicted age at the birth of the first child associated with varying levels of income volatility and average income, for an otherwise average respondent. Starting from mean levels of all the variables, a standard deviation increase in conditional income volatility is associated with a 0.28 year $(1.1 \%)$ delay in the decision to have started a family. This change should be compared with a similar increase in the level of average income, which is associated with a 0.31 year (1.3\%) 
acceleration of the decision to have started a family. Thus, as with the home purchase decision, changes in income volatility, conditional on average and current income, are associated with changes in the timing of the decision to have children comparable to those associated with changes in the level of income.

Figure 4: Predicted conditional age at birth of first child, by income volatility and average income, average white male age 30-62 in the PSID

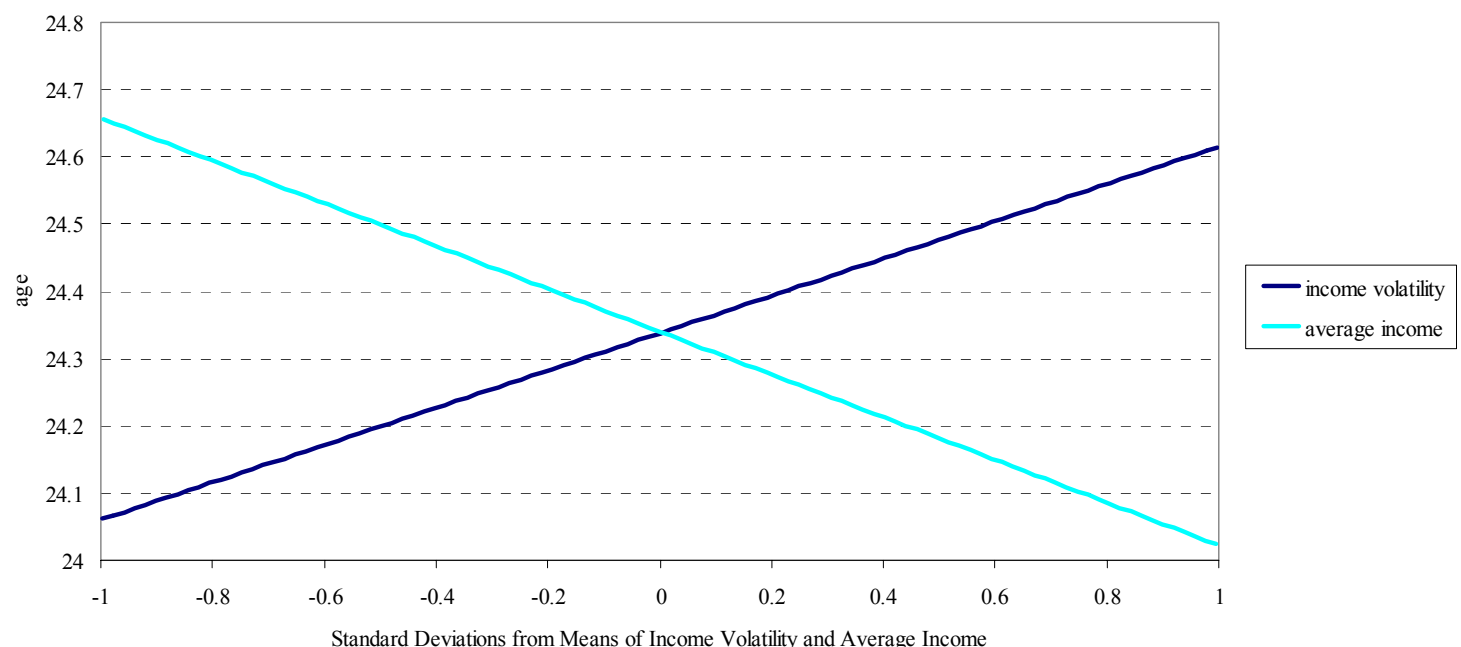

Predicted ages based on a regression of age at birth of first child on current age, education, average income, current income, past income volatility, marital status, number of children and number of income observations. Predictions condtion on sample averages of other variables.

This evidence is still at best suggestive, all the more so because home ownership, the decision to start a family and income patterns are simultaneously shaped by a variety of life decisions. A more systematic empirical investigation of the importance of consumption commitments is clearly needed to determine the importance of consumption commitments. Such work is beyond the scope of this paper, but is the subject of subsequent work.

\section{The Model}

We are interested in the incentives to smooth the consumption of some goods in order to take advantage of consumption commitments. We examine a model in which all other incentives to smooth consumption are absent, and 
in which there are no other opportunities to smooth. Hence, our consumer will be risk neutral and will be stripped of intertemporal considerations. The consumer will be unable to save, borrow, or purchase insurance. Consumption commitments will last for only one period. We claim not that the excluded considerations are unimportant, but that it is easier to study the commitments in which we are interested in their absence.

There are three goods, including

- a non-commitment consumption good, denoted by $x$ and with a price that is normalized to unity;

- labor, whose price is denoted by $w$;

- a consumption good, denoted by $z$.

We think of $z$ as a composite of those goods whose cost can be reduced by making consumption commitments, with good $x$ a composite of the remaining consumption goods. In particular, we will consider some cases in which consumption commitments are quite important, in the sense that utility depends heavily (or, in the limit, exclusively) on good $z$. In doing so, we do not have in mind a consumer who sits doing nothing in an empty house (to which the consumer has a mortgage commitment), but rather a consumer who has a broad array of opportunities to reduce the cost of consumption via purchasing patterns that involve inflexibilities. The lack of flexibility may arise from long-term contracts, advance-purchase discounts, buying in bulk, and so on.

The consumer lives for $N$ periods and is endowed with one unit of labor in each period, which the consumer inelastically supplies to the market. Letting $U(x(t), z(t))$ be a utility function defined over the period- $t$ consumption levels $x(t)$ and $z(t)$, the consumer maximizes

$$
\sum_{t=1}^{N} U(x(t), z(t)),
$$

subject to a budget constraint. We assume that the utility function has strictly negative own-second derivatives and is homogeneous of degree one, so that consumers are risk neutral (cf. Kihlstrom and Mirman [14]). Common examples, such as Cobb-Douglas utility functions, satisfy these assumptions. Given the finite lifetime, we adopt the convenience of assuming there is no discounting. The consumer can neither save nor borrow, and hence must balance the budget within each period. 
In each period $t$, one of two states is independently (across periods) drawn, state 1 or "good" and state 2 or "bad," with probabilities $p \in(0,1)$ and $1-p$. The consumer receives a wage $w_{1}(t)$ in state 1 . In state 2 , the consumer receives a wage $w_{2}(t)$ if employed, but is unemployed with probability $\rho(t)$ in period $t$. An unemployed consumer has no income and consumes nothing.

A consumption plan specifies quantities $x_{1}(t)$ and $x_{2}(t)$ as well as $z_{1}(t)$ and $z_{2}(t)$ to be consumed in each state and in each period, if employed. The plan also specifies whether commitments are involved in the consumption of the latter good. In each period $t$ and regardless of whether commitments were made in other periods, good $z$ can be obtained with no commitments at price $c_{N}$, with different quantities purchased in different states, so that $z_{1}(t)$ need not equal $z_{2}(\mathrm{t})$. If good $z$ is consumed via commitments in period $t$, then the price is $c_{C}<c_{N}$, but the consumption of good $z$ in that period cannot depend upon the state, i.e., $z_{1}(t)$ must equal $z_{2}(t) .{ }^{6}$ This restriction reflects a high cost of adjusting the quantity of consumption commitments that can arise for a number of reasons. ${ }^{7}$ The potential advantage of consumption commitments spring from this cost difference. ${ }^{8}$

\footnotetext{
${ }^{6}$ One could imagine a consumer who is not at risk of being laid off committing to a quantity of $z$, and then supplementing this consumption in state 1 with additional units of $z$ purchased at the non-commitment price $c_{N}$. For some commitment goods, this brings relatively little flexibility. Once one has chosen to obtain a particular advanced education, for example, there is only a limited opportunity to enhance its quality by supplementing with private tutoring and music lessons. Other cases appear to provide more flexibility. Having purchased a house, one can still rent weekends at the local Hilton. However, the latter might better be viewed as the consumption of vacation services rather than housing, and hence to be captured by the increased consumption of good $x$. We assume throughout that any increased consumption made possible by the good state of nature is captured by the non-commitment good $x$.

${ }^{7}$ In the case of housing, there may be transactions costs, including realtors' fees. There may also be capital losses associated either with idiosyncratic features of a home or with moral hazard and adverse selection considerations arising out of past maintenance and unobservable problems with the property. The logic underlying our results would not be qualitatively changed if we substituted a less extreme rigidity in consumption levels, though the analysis would be less transparent.

${ }^{8}$ In the case of housing, the advantage of owning rather than renting reflects (at least) two factors. The first is that owners have an incentive to care for housing that renters do not, reflected in construction costs (with rented housing requiring features designed to ensure durability that would be unnecessary in the presence of proper care) and in the form of higher maintenance costs for rented housing. Second, there are cost savings in being able to match the characteristics of the housing to the tastes of the buyer. We would have evidence for this latter motivation if we asked the owner of a newly-constructed custom home, "What would you have to spend to buy a speculation-built home that you like at least as well as your custom home?", and obtained a price higher than the cost of
} 
A consumer who faces a risk of unemployment in period $t$, in the form of a positive probability of a layoff, cannot make consumption commitments in period $t$. Our interpretation is that unemployment would trigger adjustment costs, including possibly default, that are sufficiently onerous as to make commitments suboptimal when facing a layoff risk.

In each period, consumption (and, in Section 5, employment) plans are first set, including the choice of whether to make consumption commitments. Shocks are then realized, specifying whether the state is the good or bad state and whether the consumer is laid off in the latter case. Consumption then occurs.

\section{Endogenous Risk Aversion}

\subsection{Risk aversion}

In this section, we examine the sense in which consumption commitments cause risk attitudes to be endogenously determined. None of the temporal structure of the model is required for this argument. It suffices to consider a single period in the consumer's lifetime, or a consumer who lives only for one period, and hence to dispense with the time subscript $t$. To concentrate on consumption decisions, we assume that the consumer faces no layoff risk, receiving wages $w_{1}$ and $w_{2}$ in states 1 and 2 .

If the consumer makes no consumption commitments, then the consumer's problem is:

$$
\max _{x_{1}, z_{1}, x_{2}, z_{2}}\left[p U\left(x_{1}, z_{1}\right)+(1-p) U\left(x_{2}, z_{2}\right)\right]
$$

subject to

$$
\begin{aligned}
& x_{1}+c_{N} z_{1}=w_{1} \\
& x_{2}+c_{N} z_{2}=w_{2} .
\end{aligned}
$$

This maximization problem can be decoupled into two problems, one for each state. The solution to both problems can be described by an indirect utility function that is linear in the wage, and that we can therefore take to simply equal the wage. Hence, units of measurement can be chosen so that the utility of receiving wage $w_{1}$ in the good state is

$$
U\left(w_{1}\right)=w_{1}
$$

the current home. 
and the utility of receiving wage $w_{2}$ in the bad state is

$$
U\left(w_{2}\right)=w_{2}
$$

This consumer is risk neutral.

The problem facing a consumer who chooses to make consumption commitments is

$$
\max _{x_{1}, x_{2}, z}\left[p U\left(x_{1}, z\right)+(1-p) U\left(x_{2}, z\right)\right]
$$

subject to

$$
\begin{aligned}
& x_{1}+c_{C} z=w_{1} \\
& x_{2}+c_{C} z=w_{2} .
\end{aligned}
$$

We cannot decompose this problem into two state-specific maximizations. Instead, this maximization problem leads to a pair of indirect utility functions $U_{1}\left(w_{1}, w_{2}\right)$ and $U_{2}\left(w_{1}, w_{2}\right)$ giving utility in states 1 and 2 , as a function of the wage in each state. We have the following proposition, the proof of which is left to Section $8 .^{9}$

Proposition 1 Let

$$
\bar{w}=p w_{1}+(1-p) w_{2} .
$$

Then for $\left(w_{1}, w_{2}\right)$ inducing interior optima and with $w_{1} \neq w_{2}$,

$$
p U_{1}(\bar{w}, \bar{w})+(1-p) U_{2}(\bar{w}, \bar{w})>p U_{1}\left(w_{1}, w_{2}\right)+(1-p) U_{2}\left(w_{1}, w_{2}\right) .
$$

This result indicates that a consumer who makes consumption commitments will strictly prefer to smooth wages across states, making the consumer effectively risk averse in wages. Fluctuating wages induce variations in the consumption of the noncommitment good $x$ across states, while the quantity of the commitment good $z$ is necessarily held fixed. However, the utility function $U(x, z)$ is concave in $x$ for a fixed quantity of $z$. The consumer would accordingly prefer to smooth the consumption of $x$ by smoothing wages across states. Risk aversion is thus not solely a property of preferences, but emerges from the interplay of preferences and the consumption technology.

The following (proven in Section 8) illustrates the effects of consumption commitments:

\footnotetext{
${ }^{9}$ Intuitively, when facing wage $\bar{w}$, the consumer has the option of purchasing the same quantity of good $z$ as when facing wage profile $\left(w_{1}, w_{2}\right)$, and hence consuming an amount $x$ in each state equal to the expected value of such consumption under $\left(w_{1}, w_{2}\right)$. This increases utility, since $U(x, z)$ is strictly concave in $x$ for a fixed $z$.
} 
Lemma 1 If the consumer makes consumption commitments, then

$$
w_{1}>w_{2} \Rightarrow \frac{\lambda_{1}}{\lambda_{2}}<\frac{p}{(1-p)}
$$

where $\lambda_{1}$ and $\lambda_{2}$ are the multipliers attached to the constraints (3)-(4).

The multipliers $\lambda_{1}$ and $\lambda_{2}$ can be interpreted as the marginal utility of income in states 1 and 2 , in the sense that $\lambda_{i}$ gives the rate at which the maximum expected utility $\left[p U\left(x_{1}, z\right)+(1-p) U\left(x_{2}, z\right)\right]$ changes as $w_{i}$ changes. If the consumer made no consumption commitments, then the consequent in (7) would hold with equality. The marginal effect on expected utility of a variation in the state- $i$ wage would be proportional to the probability of an outcome in which state $i$ occurs. If instead good $z$ is consumed via commitments, then condition (7) indicates that if wages are higher in state 1 , then the ratio of the marginal utilities of the incomes $w_{1}$ and $w_{2}$ fall short of the ratio of the probabilities with which these incomes are received. Hence, the rigidities introduced by commitments cause extra income in the high-wage state to have a relatively smaller effect on expected utility.

\subsection{Risk Bunching}

We now bring the temporal structure of the model into the picture, asking how a consumer who faces a given lifetime layoff risk would like to have that risk distributed across periods. The following section shows why the consumer might face such layoffs. Here, we show that the result is a preference for risk bunching.

Consider a consumer who lives for $N>1$ periods. Assume that the consumer receives a wage of $w_{1}$ in the good state and $w_{2}<w_{1}$ in the bad state, the latter conditional on being employed. Suppose over the course of the consumer's working lifetime, the consumer is constrained to face an average layoff risk, conditional on the bad state, of $\bar{\rho}$. Hence, it must be the case that

$$
\sum_{t=1}^{N} \rho(t)=\bar{\rho} N .
$$

We are interested in which values $\rho(1), \ldots, \rho(N)$ the consumer would prefer, subject to the constraint on their sum. Let $\tau$ be an integer satisfying

$$
\tau \leq \bar{\rho} N<\tau+1
$$

Then we have: 
Proposition 2 The consumer's expected utility is maximized by choosing $\tau+1$ values from $\{1, \ldots, N\}$, denoted $t_{1}, \ldots, t_{\tau+1}$, and letting the layoff risks be:

$$
\begin{array}{rlrl}
\rho\left(t_{k}\right) & =1 & k=1, \ldots, \tau \\
\rho\left(t_{\tau+1}\right) & =\bar{\rho} N-\tau & & \\
\rho\left(t_{k}\right) & =0 & & k=\tau+2, \ldots, N .
\end{array}
$$

Hence, the consumer concentrates the layoff risk in as few periods as possible, enduring a unitary probability of layoff (modulo integer problems) in such periods (conditional on the bad state), in return for facing no layoff risk in the other states. ${ }^{10}$ We provide a sketch of the proof, which is straightforward (and hence omitted). The consumer can make consumption commitments in period $t$ if and only if the consumer faces no layoff threat. Conditional on facing the threat of layoff, the consumer is risk neutral, implying that the consumer is indifferent about how the layoff threat is distributed among those periods for which it is positive. Maximizing utility then requires minimizing the number of periods in which the consumer is liable to layoffs.

This preference for risk bunching is another feature of the consumer's effective risk aversion. The consumer's first choice would be to bear no employment risk. Given that some such risk is to be borne, the consumer's preferences is to eliminate this risk from as many periods as possible.

\section{Employment Contracts}

We turn next to the interaction between consumption and earnings decisions. We begin by embedding the consumer in a simple economy.

\subsection{The Labor Market}

The economy operates for a countably infinite number of periods. The economy contains a unit continuum of infinitely-lived firms that produce good

\footnotetext{
${ }^{10}$ There are other optimal arrangements, but none of them features a layoff risk in more than $\tau+1$ periods. For example, any permutation of the probabilities of layoff in the proposition would also maximize the consumer's expected utility. In a richer model one would expect that the particular sequence of layoffs would be strictly better than some permutation under a variety of plausible circumstances: (i) if there were intertemporal rigidities, the consumer would prefer that the periods of security be consecutive, or, (ii) if there was firm-specific human capital that increased over the worker's tenure, firms would prefer laying off younger workers.
} 
$x$. The owners of these firms are risk neutral and consume only good $x$, and hence maximize expected profits. There is a continuum of producers of the commitment good who have access to a constant-returns-to-scale production process that uses only good $x$ as an input. As a result, these producers will earn no profits (and will occupy very little of our attention, with a reference to "firms" always being a reference to producers of good $x$ ). At any instant, there is a mass of size $1 / N$ of consumers (or, interchangeably, "workers") of age $t, t=1, \ldots, N$, of their $N$-period lives.

Each firm in each period can be in one of two states, state 1 or "good" or state 2 or "bad," with probabilities $p \in(0,1)$ and $1-p$, independently across periods. There is no aggregate uncertainty, so precisely proportion $p$ of the firms are in the good state in each period. ${ }^{11}$ Output in period $t$ is determined by the number of workers the firm employs in that period, $n(t)$, and the state. The production function in state 1 is given by $f$ and in state 2 by $g$, where $f(n)>g(n)$ and $f^{\prime}(n)>g^{\prime}(n)>0$ for all quantities of employment $n$. We interpret state 2 as an adverse productivity shock. ${ }^{12}$

At the beginning of each period $t$, firms post labor contracts, which workers either accept or reject to remain idle (at reservation utility $\bar{U}$ ). A labor contract specifies wages $w_{1}(t)$ and $w_{2}(t)$ to be paid in the good $\left(w_{1}(t)\right)$ and bad $\left(w_{2}(t)\right)$ states as well as the proportion $\rho(t)$ of employees that will be laid off in the bad state. In addition, the contract must specify how the risk of unemployment is to be distributed across employees.

The firm faces four constraints in setting these contracts. First,

$$
\rho(t)=\frac{n_{1}(t)}{n_{1}(t)+n_{2}(t)},
$$

where $n_{2}(t)$ is the amount of labor hired in state 2 and $n_{1}(t)+n_{2}(t)$ is the amount of labor hired in state 1 . Hence, $n_{1}(t)$ is the extra amount of labor hired in state 1 . In principle, $n_{1}(t)$ could be negative, but it will never be optimal to hire more labor in the bad state than in the good state. The case of $n_{1}(t)=0$ corresponds to no unemployment risk.

The next two constraints we impose are that the firm cannot make payments to unemployed workers, and that firms cannot pay a wage in state $i$ that exceeds the marginal product of labor in state $i$. These restrictions

\footnotetext{
${ }^{11}$ Because we do not require draws to be independent across firms, it is straightforward to construct a probability space with these features.

${ }^{12}$ What is important in our model is that shocks affect the marginal profitability of workers; nothing in our analysis would be substantively different had we instead modeled firms as being subject to demand shocks that decreased the marginal revenue product.
} 
might be interpreted as reflecting moral hazard considerations. Making payments in excess of marginal products makes it too tempting for the firm to fire workers for alleged nonperformance, while unemployment compensation provides insufficient incentives to undertake home production or seek alternatives. Additionally, firms may face a limit on their ability to borrow money to pay workers above their marginal product, with the constraint that firms never pay above the marginal product viewed as the limiting case.

The constraint that wages not exceed marginal products is essential to our analysis. In its absence, an argument analogous to the "wage bill" argument of Akerlof and Miyazaki [1] would ensure that the optimal labor contract completely insures the worker against risk, featuring no wage fluctuations and no unemployment. Our interest is in studying how optimal contracts balance wage and unemployment risk, in the presence of some imperfection that potentially forces the contract to contain some risk. There are likely to be other frictions under which optimal contracts feature some risk, which we expect would interact with consumption commitments in similar ways.

We consider two possible ways that layoffs could be allocated among workers in the event of a bad state. The employment contract may specify that each worker is laid off with probability $\rho(t)$ in the bad state. We refer to this as the random-layoff contract. Alternatively, the contract may specify that the youngest $n_{1} /\left(n_{1}+n_{2}\right)$ proportion of workers is laid off with probability one, while others retain employment. We refer to this as a concentrated layoff contract. ${ }^{13}$ Given that workers who make no consumption commitments are indifferent as to the timing of layoffs, while those who make commitments prefer to bunch them (cf. Proposition 5.2), it suffices to consider these two possibilities. We say the workers who will be laid off in the bad state are "at risk" of a layoff, while the others are immune. Notice that "youngest" is unambiguous in our model, where there is perfect correlation between a worker's age and her tenure with the firm. When turning the empirical work in Section 5.3, we interpret youngest in terms of tenure with the firm.

Finally, we assume that in each period, all workers who remain employed

\footnotetext{
${ }^{13}$ Let $\bar{n}$ be the largest integer smaller than $N n_{1} /\left(n_{1}+n_{2}\right)$. Then all workers of age $\bar{n}$ and younger are laid off, as well as $N n_{1} /\left(n_{1}+n_{2}\right)-\bar{n}$ of the next youngest age. It simplifies the calculations considerably to assume that the latter workers take a random draw at the beginning of the period, indicting with probability $n_{1} /\left(n_{1}+n_{2}\right)-\bar{n} / N$ that they will be laid off if the state is bad (and hence that they cannot make consumption commitments), and with the complementary probability that they are immune from layoffs and can make commitments.
} 
at the firm after the state of nature is realized receive the same wage. In particular, wages do not vary with workers' ages. When layoffs are random, this is not a binding constraint. When layoffs are concentrated, we are constraining the good-state wage $w_{1}$ to not depend upon whether a worker is at risk of being laid off. This simplifies the calculations, but does not play an important role in the results.

We examine a steady state of this economy, and assume that firms evaluate their payoffs via a limit-of-the-means criterion. As a result, firms offer the same employment contract to new workers in each period, maximizing the profit obtained from a representative period. This employment contract offers wages that are state contingent but do not vary across periods, with layoff probabilities that may vary with workers' ages (i.e., tenure), but again do not vary across periods. The contract is subject to the constraint that each cohort of workers receive an expected utility, over their lifetime, equal to the reservation utility level.

Each worker's consumption plan specifies quantities that are state contingent but that again do not depend on the time period, including quantities $x_{1}$ and $x_{2}$ as well as $z_{1}$ and $z_{2}$ to be consumed in each state, if employed. The plan also specifies whether commitments are involved in the consumption of the latter good, bearing in mind the constraint that commitments cannot be made by those at risk of being laid off.

\subsection{Risk Bunching}

We now demonstrate how optimal employment contracts can exploit economies of scale in bearing risk.

No consumption commitments. Suppose first that consumers make no consumption commitments. They are then risk neutral, and will be indifferent between concentrated and random layoffs. We can assume that in each period, each worker faces the layoff risk $\rho$, which must equal $n_{1} /\left(n_{1}+n_{2}\right)$. Risk neutrality also allows us to initially ignore the constraints that wages not exceed marginal products in our derivation of an optimal employment 
contract. ${ }^{14}$ In a steady state, we can express the firm's problem as

$$
\max _{n_{1}, n_{2}, w_{1}, w_{2}} p\left[f\left(n_{1}+n_{2}\right)-w_{1}\left(n_{1}+n_{2}\right)\right]+(1-p)\left[g\left(n_{2}\right)-w_{2} n_{2}\right]
$$

subject to

$$
p w_{1}+(1-p) \frac{n_{2}}{n_{1}+n_{2}} w_{2} \geq \bar{U} .
$$

The maximand gives the firm's expected profit in each period. The constraint is similarly the worker's expected utility in each period. ${ }^{15}$ The constraint requires that the worker's expected utility of the labor contract be at least $\bar{U}$, the reservation utility level that clears the labor market.

The next proposition, the proof of which is in Section 8, characterizes the equilibrium employment contract when workers do not make consumption commitments.

Proposition 3 The equilibrium employment contract offered to workers who do not make consumption commitments features no layoffs, and $w_{1}>w_{2}$, where each wage equals the marginal product of labor in the corresponding state.

The intuition for this result is straightforward. Consider a candidate contract in which $n_{1}>0$, so that some employees are laid off in the bad state. We can exploit workers' risk neutrality to adjust $w_{1}$ and $w_{2}$, preserving expected utility and expected wage payments (and hence profits), until the wage in state 1 equals its marginal product. Now consider a reduction in $n_{1}$, the extra labor employed in the good state. Since the marginal product of labor equals the wage rate in the good state, this marginal reduction has only a second-order effect on profits. However, it reduces the probability of unemployment in the bad state, yielding a first-order increase in utility.

\footnotetext{
${ }^{14}$ Given any optimal contract in which neither wage equals the corresponding marginal product, one wage must exceed and one fall short of the relevant marginal product, since otherwise hiring either more or less labor would increase profits. We can then smooth wages, preserving expected wage payments, until one wage hits the relevant marginal product. If the other wage exceeds its marginal product, then we have too much labor. If it falls short, then we can smooth employment somewhat less, causing both wages to fall short of their marginal products and allowing us to optimally hire more labor. Hence, for any optimal contract, we can find an equivalent contract in which wages equal marginal products, allowing us to dispense with the explicit provision of this equality in our derivation.

${ }^{15}$ Recall that $n_{2} /\left(n_{1}+n_{2}\right)$ is the probability of being employed in the bad state and that $w_{1}$ and $w_{2}$ can be viewed as indirect utility functions, giving the utility of receiving a wage of $w_{i}$ in state $i$ when consuming rental housing.
} 
This first-order increase in utility can be exploited by reducing wages and hence increasing profits. A candidate contract involving layoffs thus cannot be optimal.

Consumption commitments. We now examine the optimal employment contract when workers make commitments. This is possible only if there are some ages at which workers do not face layoffs, in which case it is optimal to concentrate layoffs. Workers who face no layoff risk make consumption commitments, while workers facing a risk of layoff purchase good $z$ on the spot market, without commitments, at price $c_{N}$.

The firm's optimal strategy must solve

$$
\left.\max _{n_{1}, n_{2}, w_{1}, w_{2}} p\left[f\left(n_{1}+n_{2}\right)-w_{1}\left(n_{1}+n_{2}\right)\right]+(1-p)\left[g\left(n_{2}\right)-w_{2} n_{2}\right)\right]
$$

subject to

$$
\begin{aligned}
\frac{n_{2}}{n_{1}+n_{2}}\left(p U_{1}\left(w_{1}, w_{2}\right)+(1-p) U_{2}\left(w_{1}, w_{2}\right)\right)+\frac{n_{1}}{n_{1}+n_{2}} p w_{1} & \geq \bar{U} \\
g_{n_{2}}^{\prime}-w_{2} & \geq 0 .
\end{aligned}
$$

The second constraint embodies the restriction that the wage in state 2 not exceed the marginal product of labor in that state. A similar constraint applies to state 1 but does not bind in equilibrium. ${ }^{16}$ We then have the following proposition, the proof of which is left to Section 8:

Proposition 4 If workers make consumption commitments and are subject to concentrated layoff risks, then the equilibrium employment contract features a wage rate $w_{2}$ that equals the marginal product of labor in state 2 and a wage $w_{1} \geq w_{2}$ that is below the marginal product in state 1 .

Again, we see that workers who make consumption commitments are effectively risk averse. As a result, the firm smooths the wages across states. For example, suppose that consumers make commitments and that wages equal marginal products in both states. Consider a marginal reduction in the quantity of labor hired, while retaining the ratio of state- 1 to state- 2 employment. Because wage rates and the layoff risk (of zero) are retained, the workers' utilities are unaffected. Because wages equal marginal products, this reduction in employment has only a second-order effect on profits.

\footnotetext{
${ }^{16}$ Consumption commitments have the effect of making consumers risk averse, introducing an incentive for the firm to smooth wages. The constraint that wages not exceed marginal products will then bind in the relatively low-marginal-product state 2 .
} 
However, the employment reduction increases marginal products, relaxing the constraints on wages. This allows the firm to engage in wage smoothing that preserves expected wage payments but increases the utility of the effectively risk averse workers. This in turn relaxes the workers' participation constraint, allowing the firm to make profit-enhancing adjustments in the employment contract. Thus, it cannot be the case that an optimal fullemployment contract sets both wages equal to the corresponding marginal product. The premium on smoothing wage rates ensures instead that the marginal-product constraint binds in state 2 but not state 1 .

Optimal layoffs. We next combine the firms' and workers' decisions to determine the circumstances under which the equilibrium calls for layoffs. The intuition is that layoffs allow workers to make better use of consumption commitments when they are not at risk of being laid off, by smoothing wages and hence making it less burdensome that the same quantity of the commitment good be consumed in the good and bad state.

Layoffs are likely to be optimal when consumption commitments are important. To get an idea of what this involves, return to the motivation for our model. For some components of consumption, such as food and clothing, one can modify consumption plans relatively cheaply. There are other components of consumption for which adjustments are quite costly. An individual whose consumption plan includes listening to rock music will likely have purchased a stereo and a number of compact disks. These purchases might be quite sensible when considering the average cost per song played over the expected lifetime of the disks. However, given the relatively low resale value of such items, a shock that requires the individual to reduce his expenditure on such music by $\$ 10$ might entail selling the machine and all the compact disks on eBay.

More generally, services derived from durable goods carry higher adjustment costs than nondurable goods. To the extent that durable goods constitute a large or increasing portion of expenditures, consumption commitments will be important. In our model, this is captured by the relative importance of the goods $x$ and $z$ in the utility function. It will be convenient to focus on the polar case in which all goods involve commitment. We say that a consumer is fully vulnerable to risk if there is a constant $k$ such that ${ }^{17}$

$$
U_{1}\left(w_{1}, w_{2}\right)=U_{2}\left(w_{1}, w_{2}\right)=k w_{2} .
$$

\footnotetext{
${ }^{17}$ We assume that $w_{1} \geq w_{2}$. At this point, this is simply a naming convention, though we will subsequently derive this inequality as an equilibrium condition.
} 
In this case, only good $z$ matters: any income above $w_{2}$ received in state 1 provides no additional utility. Such a consumer spends the entire effective income of $w_{2}$ in each state on purchasing good $z$, ensuring that the consumer's utility can be written as $k w_{2}$ for some $k>1 .{ }^{18}$ Our interpretation of a consumer who spends all of his income on good $z$ is not necessarily that there are no other consumption goods, but rather that virtually everything the agent does consume is purchased via a commitment. ${ }^{19}$

We now work with this extreme case in which workers are fully vulnerable to risk. We also assume a particular relationship between the production function in the good and bad states, namely that there exists a constant $\alpha>1$ such that

$$
f(n)=\alpha g(n) .
$$

To consolidate notation, let $\theta(n)=-g^{\prime \prime}(n) n / g^{\prime}(n)$ be the elasticity of the marginal product of labor in the bad state. Then we have:

Proposition 5 Let workers be fully vulnerable to risk (i.e., all consumption involves commitments) and let $f(n)=\alpha g(n)$ for some $\alpha>1$. Then optimal contracts will feature layoffs if

$$
p(\alpha-1) \theta\left(n^{*}\right) k>(k-p)\left(\alpha-1+\theta\left(n^{*}\right)\right),
$$

where $n^{*}$ is the optimal quantity of labor hired to a contract with no layoffs.

To interpret this condition, notice first it is more likely to hold as $p$ is close to 1. This is expected, as the more likely is the good state, the more valuable will it be to trade the possibility of bad-state layoffs for more desirable good-state wages. Hence, consider the limiting case of $p=1$ :

$$
(\alpha-1) \theta\left(n^{*}\right) k>(k-1)\left(\alpha-1+\theta\left(n^{*}\right)\right) .
$$

This condition holds for all values of $k>1$ whenever $(\alpha-1) \theta>\alpha-1+\theta$, which we can rearrange to give

$$
(\alpha-2)\left(\theta\left(n^{*}\right)-1\right)>1 .
$$

\footnotetext{
${ }^{18}$ Notice that $k>1$, given the normalization that we have adopted for the utility function in the case in which the consumer makes no commitments and our assumption that commitments reduce the cost of consumption.

${ }^{19}$ Even quite ordinary purchases might involve commitments. For example, commitments arise when items are purchased rarely, but in large quantities, to take advantage of fluctuating prices. Completely committed consumption is unrealistic, but is analytically convenient. The results will continue to hold in less extreme cases, though with somewhat more cumbersome statements, as long as consumption commitments are sufficiently important.
} 
A large value of $\theta$ indicates that the marginal product of labor is relatively elastic. Hence, a small reduction in bad-state employment (and hence layoff risk) yields a relatively large relaxation in the wage constraint, again allowing a relatively favorable trade-off between layoff risk and increased good-state wages. A large value of $\alpha$ indicates that the marginal product of labor is much higher in the good than in the bad state, making it valuable for the firm to incur the costs of layoffs in order to shift employment from the bad to the good state and ensuring that only modest layoffs need be introduced in order to compensate for the higher wage costs. ${ }^{20}$

The potential optimality of layoffs arises from an interplay between the worker's preferences and the firm's technology. First, a worker who makes consumption commitments is effectively risk averse, preferring to smooth wages across states. We see this in Proposition 4, indicating that the firm optimally offers a wage that varies less than does the worker's marginal revenue product, even without layoffs. The potential advantage of layoffs is that they relax the upper bound on the wage in state 2 , allowing further wage smoothing. If consumption commitments are very important, the enhanced smoothing when not at risk of a layoff can compensate for the additional layoff risk.

Proposition 5 explores this possibility by assuming that consumption commitments are of paramount importance, in the sense that all consumption is subject to commitment. But in this case, the firm optimally sets a wage that does not vary across states. This is as smooth as one can get. What additional benefits do layoffs bring? Once again, the constraints on wages posed by the firm's technology come into play. Introducing layoffs allows the firm to decrease employment in state 2 and hence increase the wage, which binds against the state- 2 marginal revenue product of labor. The worker and the firm may both be willing to trade the layoff risk for this increased wage. The worker would not be willing to do so if the firm did not capture some efficiency gains in the process. ${ }^{21}$ Nor would the firm be

\footnotetext{
${ }^{20}$ Condition (12) involves the endogenous quantity $n^{*}$, though some production functions will yield bounds on $\theta(n)$ ensuring (12) for all $n$. If $(\alpha-2)(\theta-1)>1$ fails, (12) will still hold as long as $k$ is not too large. The latter requirement may appear paradoxical, but if $(\alpha-1) \theta>\alpha-1+\theta$ fails, then increasing the good-stage wage requires a substantial layoff risk which, for large values of $k$, is quite costly.

${ }^{21}$ Suppose the firm's revenue were to remain constant, and hence so must its total expected payment to the worker if its profits are not to decrease. Would the worker then be willing to reduce the probability of a payment in order to increase the wage rate? A worker who makes no consumption commitments would be indifferent over any such adjustment. For a worker who makes such commitments, such an adjustment holds expected payments constant, while decreasing the proportion of those payments that can
} 
willing to simply decrease employment in both states, increasing the wage rate without incurring layoffs, since the worker's expected marginal revenue product exceeds the wage rate, ensuring that such an adjustment decreases profits. However, introducing layoffs allows efficiency gains by transferring workers from the low-marginal-product state 2 to state 1 . This opens the possibility that the firm may be able to trade layoffs for higher wages at a rate that consumers find beneficial.

To summarize, if consumption commitments are important, there are economies of scale in bearing risk. If some risk is inevitable, then consumers prefer to concentrate the risk in as few periods as possible, cushioning its effects by making no commitments. The payoff from doing so is the relative freedom from risk in other periods, enabling consumers to commit to consumption. If the implicit exchange rate is favorable, workers may prefer employment contracts that feature layoff risks early in their tenure, in return for an enhanced ability to make consumption commitments later. In response to the question raised in the introduction, workers for whom consumption commitments are important may prefer relatively rigid wages and concentrated layoff risk to guaranteed employment at flexible wages.

Lurking behind this result is the observation that layoffs are more likely to be optimal the less likely is state 2 (the larger is $p$ ). The less likely is the bad state, the less costly is the trade-off between bad-state layoffs and higher wages, and hence the more likely are the former to be optimal.

Pursuing this intuition, we expect the magnitude of the optimal layoff risk, conditional on the bad state occurring, to decline as state 2 becomes more likely. A more likely adverse productivity shock can thus make it more likely that the firm will impose some layoffs, but also that these layoffs will be concentrated among a smaller group of workers when they occur. Those workers young enough to be laid off in the bad state face a higher layoff risk when the bad state is more likely, but there will be fewer such workers at risk. With the help of some additional structure, we verify this relationship in the following proposition, the proof of which is in Section 8.

Proposition 6 Let workers be fully vulnerable to risk, let $f(n)=\alpha g(n)$ for some $\alpha>1$, let $g(n)=\ln (n)$, and suppose that the optimal contract features a positive layoff risk. Then the optimal contract corresponding to a larger value of $p$ (less likely adverse productivity shock) features a larger layoff probability conditional on the bad state occurring.

be used to make commitments (since commitments cannot be made when one is subject to layoff risk), decreasing expected utility. 


\subsection{Evidence of Optimal Risk Bunching}

Proposition 6 suggests a distinctive influence of consumption commitments on the structure of optimal layoffs: in sectors with a higher incidence of layoffs, those layoffs should be more concentrated among younger (lower tenure) workers. In this section, we argue that US data on layoffs and job tenure are consistent with this relationship. Using the Current Population Survey (CPS) biannual Displaced Workers and Job Tenure supplements, we find that in industry-occupation cells with higher rates of layoff, those layoffs are more concentrated among lower tenure workers.

Dividing workers into 22 industries, 8 occupations and 4 geographic regions, we examine data from three of the CPS supplements (1996, 1998, and 2000). We calculate the sample average probability of having been laid off in the calendar year prior to the survey for each of these industry-occupationgeography cells. ${ }^{22}$ We also determine each respondent's tenure at the last job he held or lost in the calendar year prior to the survey. We then estimate the following probit model:

$$
\operatorname{Pr}\left(\text { Layoff }_{i}\right)=\Phi\left[\beta_{0}+\beta_{1} P_{i}+\beta_{2} T_{i}+\beta_{3}\left(P_{i} \times T_{i}\right)+\beta_{4} X_{i}\right]
$$

where $\operatorname{Pr}\left(\right.$ Layoff $\left._{i}\right)$ is the probability an individual was laid off during the response period ${ }^{23}$ and:

$$
\begin{aligned}
P_{i} & =\text { sample probability of layoff for all other workers in } i \text { 's cell } \\
T_{i} & =i \text { 's tenure at the job } \\
X_{i} & =\text { a vector of other covariates }
\end{aligned}
$$

Translated into marginal effects the coefficient $\beta_{1}$ will determine the vertical intercept of the tenure-probability of layoff profile for a cell with aggregate probability of layoff $P_{i}$. The coefficients $\beta_{2}$ and $\beta_{3}$ will, in turn, determine the slope of the tenure-probability of layoff profile. We expect $\beta_{2}<0$, which is to say that workers with greater tenure are less likely to be laid

\footnotetext{
${ }^{22}$ To avoid regressing a variable on itself, for an individual, the aggregate probability of layoff in his cell represents the sample probability of layoff among other workers in his cell.

${ }^{23}$ The supplemental surveys each collect data on occupation and job tenure from the workers in approximately 50,000 households. The surveys also ask workers at least 20 years old "During the last 3 calendar years ... did you lose a job, or leave one because: your plant or company closed or moved, your position or shift was abolished, insufficient work or another similar reason?" We consider as laid off all workers who answer yes to this question, except those who indicated that they lost or left their job because it was seasonal work. We exclude all occupations in private households, or on farms.
} 
off. Our primary hypothesis is that $\beta_{3}<0$, indicating that layoffs are more concentrated among low-tenure workers when the probability of a layoff is relatively high.

Restricting attention to the 1035 cells in which we have at least 25 observations, Table [1] presents the estimated marginal effects from this probit. $^{24}$ Standard errors are clustered at the level of the cell. The first row

Table 1: Marginal Effects from Probit Model of the Probability of Layoff in the Previous Calendar Year, CPS 1996, 1998, 2000

\begin{tabular}{|l|c|c|c|}
\hline & $(1)$ & $(2)$ & $(3)$ \\
\hline \hline Aggregate probability of layoff in cell & 0.331 & 0.333 & 0.305 \\
& $(0.0244)$ & $(0.0243)$ & $(0.0251)$ \\
\hline Tenure & -0.0020 & -0.0021 & -0.0021 \\
& $(0.0002)$ & $(0.0002)$ & $(0.0002)$ \\
\hline (Prob. of layoff) $\times($ Tenure $)$ & -0.0080 & -0.0080 & -0.0082 \\
& $(0.0038)$ & $(0.0038)$ & $(0.0038)$ \\
\hline Age & & 0.00013 & 0.00014 \\
& & $(0.00006)$ & $(0.00006)$ \\
\hline High school grad. & & & -0.0050 \\
& & & $(0.0020)$ \\
\hline College grad. & & & -0.0077 \\
& & & $(0.0012)$ \\
\hline N & 108456 & 108456 & 108456 \\
\hline Average of dependent variable & 0.030 & 0.030 & 0.030 \\
\hline Pseudo R ${ }^{2}$ & 0.042 & 0.042 & 0.045 \\
\hline
\end{tabular}

indicates that an individual's probability of layoff is, of course, positively correlated with the aggregate probability of layoff in his job. On average, a $10 \%$ increase in the aggregate probability of layoff is associated with a 3.13.3 percent increase in an average member of the cell's probability of layoff. An aggregate increase in the probability of layoff does not translate into the same increase in average probabilities of layoff for two reasons: first, our measure of risk is that for all other workers in $i$ 's cell ${ }^{25}$ and, second, the risk

\footnotetext{
${ }^{24}$ Results are qualitatively and quantitatively similar when we estimate linear probability models and logits.

${ }^{25}$ When we increase the minimum number of respondents in a cell, or when we make
} 
is distributed unevenly across workers. In particular, the results indicate the typical negative relationship between job tenure and layoff risk.

The second row of Table 1 confirms that layoffs tend to fall on workers with low tenure. Consistent with the predicted influence of consumption commitments, Row 3 of Table 1 shows that the estimated relationship between tenure and probability of layoff varies depending on the aggregate probability of layoff in the cell: jobs with higher aggregate probabilities of layoff also have steeper tenure-layoff probability profiles. ${ }^{26}$

The estimated relationships between tenure and the probability of layoff from specification (3), which conditions on the age and education of the worker, are illustrated in Figure (5) for jobs with varying aggregate probabilities of layoff.

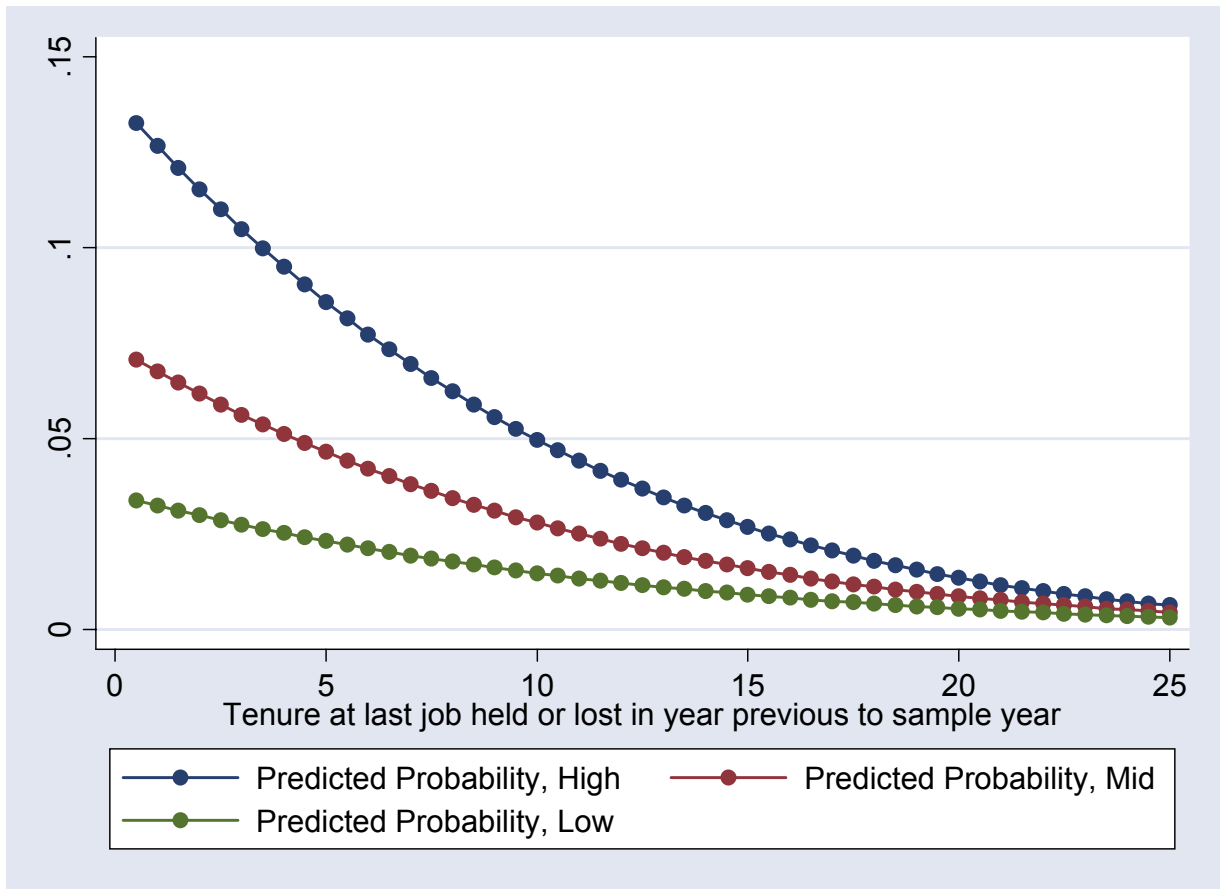

a coarser partition of workers, the coefficient on $P_{i}$ increases as the difference between the sample probability of layoff for all workers and for all other workers decreases. With higher minimums or coarser partitions, the interaction term of interest (described in the subsequent paragraph) increases in absolute magnitude and p-values decrease.

${ }^{26}$ This basic relationship is robust to the replacement of tenure with age. It is also robust to an alternative specification in which we replace our basic measure of the aggregate probability of layoff in a cell with an adjusted measure that takes into account the tenure distribution in the cell. This tenure-adjusted measure is the residual from a regression of the aggregate probability of layoff in a cell on the deciles of the tenure distribution in that cell. 
Comparing the estimates for jobs with $1 \%$ and $8 \%$ aggregate probabilities of layoff, we see that those with less than one year of tenure are at substantially higher risk of layoff in the $8 \%$ aggregate risk jobs than in the $1 \%$ aggregate risk jobs. ${ }^{27}$ This gap declines, however, with tenure. Among those with six years of tenure, the gap in the layoff probabilities between the $1 \%$ and $8 \%$ aggregate risk jobs is approximately half as large. The functional form of our estimate implies that the estimated rate at which the gap closes is same for all similar differences in aggregate layoff risk. For example, the difference between the layoff probabilities for workers with virtually no tenure in $15 \%$ aggregate risk jobs and $8 \%$ aggregate risk jobs is also cut in half after six years. Finally, at very high levels of tenure, there is almost no difference in the risk of layoff between workers at very low and very high layoff risk jobs. We interpret these findings as evidence of greater employment risk bunching in higher aggregate layoff risk jobs.

\section{Equilibrium}

We turn now to the possibility of multiple equilibria. In doing so, it is helpful to refer to consumption commitments as housing purchases.

The intuition we wish to capture is that there may be two qualitatively different kinds of equilibria. First, there may be equilibria with an established housing (or, more generally, consumption commitment) market that enables workers to make consumption commitments if they have sufficiently secure incomes. In some cases, this equilibrium will not feature layoffs, though wages will be smoother than marginal products in such an equilibrium. However, if conditions are as covered by Proposition 5, optimal labor contracts will entail concentrated layoffs, with the increased utility associated with consumption commitments and a smoother income stream (when employed) than in the no layoff contract. The second type of equilibrium is characterized by employment contracts with no layoffs, but with greater wage risk, in which workers consequently only rent housing. We refer to these as the ownership and the rental equilibria.

Given the no-commitment equilibrium, why doesn't some worker purchase housing? Our expectation is that purchased housing must be supported by a mortgage market that will operate only if the market for housing is sufficiently active. That is, we think of this equilibrium as a coordination failure: the absence of workers seeking to purchase housing inhibits the

\footnotetext{
${ }^{27}$ If aggregate risk is $8 \%$ in a job, then the area under the curve, weighted by the distribution tenures in the job, must sum to 0.08 .
} 
emergence of a mortgage market, and the absence of a mortgage market deters workers from purchasing housing. Notice, however, that creating a market for owned housing then requires not only the advent of lenders, but an overhaul of employment contracts. One might well imagine the spontaneous creation of a mortgage market if its mere existence suffices for workers to purchase housing, but may also imagine its appearance to be less likely if workers will purchase housing only after an innovation in employment contracts. $^{28}$

The possibility of multiple equilibria hinges upon the value of $c_{C}<c_{N}$. If $c_{C}$ is sufficiently close to $c_{N}$, then the cost advantage of owning housing will not compensate for the rigidity imposed by ownership. Consumers will then prefer to rent rather than own housing, and the only equilibrium will be the rental equilibrium. As $c_{C}$ falls, owning housing becomes more attractive relative to renting housing, eventually becoming sufficiently attractive as to make consumers prefer home ownership to renting. The rental equilibrium still persists, since the deviation of a single firm and its employees to an employment/consumption package featuring home ownership cannot create the necessary mortgage insurance market. However, an equilibrium in which housing is owned will also exist.

These arguments immediately give:

Proposition 7 (7.1) A rental equilibrium exists for all values of $c_{C}$.

(7.2) There exists a value $c_{C}^{*}$ such that an equilibrium in which consumers purchase housing exists (in addition to the rental equilibrium) if and only if $c_{C} \leq c_{C}^{*}$.

In the latter equilibrium, firms will offer wages that are smoother than

\footnotetext{
${ }^{28}$ Even without these considerations, transitions between the no layoff equilibrium and the concentrated layoff equilibrium may be quite difficult. If the ownership equilibrium prevails, older workers who face no layoff risk have every reason to oppose a switch to the rental equilibrium and its accompanying layoff risk. Conversely, imagine a more elaborate model allowing for a variety of consumption commitments. Suppose, for example commitments can be made to both children and housing. In the ownership equilibrium, the possibility of layoffs may force workers to avoid both children and ownership when young, with workers beyond the risk of layoff making both commitments. In the rental equilibrium, workers might have children, even when young, but avoid housing altogether, with the wage risk deterring workers from making both commitments but the immunity from layoff supporting the optimality of a commitment to children. Suppose now that the rental equilibrium prevails and a new mortgage market opens the possibility of a switch to the ownership equilibrium. Workers and firms may agree that the latter is superior ex ante. However, young workers who have already made commitments to children may be quite opposed to the switch to the ownership equilibrium.
} 
marginal products, and may optimally impose a layoff risk (if, for example, consumption is fully committed and (11) holds).

\section{Discussion}

Endogenous risk aversion. A glance at their linearly homogeneous utility functions would suggest that the consumers in our model are risk neutral. However, an inspection of the behavior of those who make consumption commitments would suggest that they are risk averse. These consumers strictly prefer to smooth their wages across the good and bad states, thereby lowering the inflexibility costs of consumption commitments.

More generally, the utility functions we can hope to observe are inferred from behavior that is the product of an interaction between preferences and the technology for converting income into consumption. Different technologies may lead us to different and potentially misleading inferences concerning risk aversion. For example, we may observe that consumers are risk neutral, concluding that insurance has no value, while the opening of an insurance market may give rise to both risk-averse behavior and active demand for insurance. $^{29}$

Concentrated risks. In one respect, workers in our economy seek risk. Conditional on facing a risk of being laid off, the worker would prefer to concentrate this risk in as few states as possible. In essence, there are economies of scale in bearing risk, inducing workers to lump risks together rather than disperse them.

Multiple equilibria. This interaction between preferences and technology can give rise to multiple equilibria. In our model, equilibrium layoffs arise if and only if consumption commitments are made, in which case workers are effectively risk averse. Suppose further that consumption commitments are easiest to make if many people make them, perhaps (for example) because a market for owned housing functions best in the presence of a secondary mortgage insurance market. Multiple equilibria then arise out of the fact that an insurance market may not open because agents are risk neutral and hence demand no insurance (while renting housing), while the opening

\footnotetext{
${ }^{29}$ Chetty ([7]) and Chetty and Szeidl ([8]) have independently made this point. Chetty demonstrated empirically the importance of commitments in estimating risk aversion, while Chetty and Szeidl show that home ownership affects portfolio composition.
} 
of the market leads to home ownership and risk averse behavior that confirms the need for the market. The interplay between an insurance market for idiosyncratic mortgage risk and widespread home ownership appears to be consistent with the housing market history reported by Fishback, Horace and Kantor [12].

Habit formation. Our model generates behavior that is similar to that of many habit formation models. ${ }^{30}$ Attanasio [2] discusses a typical habit formation model which in essence decreases an individual's effective current consumption by a constant times the individual's depreciated aggregate previous consumption. This is sometimes motivated by psychological considerations that emphasize the difference of the current consumption level from previous levels. Modeling habit formation in this way makes an individual averse to downward adjustments in consumption in a manner similar to the adjustment costs in our model. There are differences, however. First, our model would suggest nontrivial heterogeneity, linked to observable characteristics, across individuals in their aversion to downward adjustments in consumption. An individual who has made consumption commitments will be highly averse to income shocks compared to individual who has avoided commitments. Second, there is an asymmetry in the way in which adjustments affect individuals in our model that does not appear in the typical habit formation model. Negative shocks to an individual's income in our model will qualitatively differ from positive shocks: there is no analogue to the adjustment costs that a negative shock necessitates when a positive shock occurs.

Though they lead to some similar results, there are potential advantages to incorporating adjustment costs in the standard consumer model rather than adding habit-formation parameters to the utility function. First, adjustment costs of the type we consider are, in theory, more easily quantifiable. There exist data on probabilities of default on mortgages, losses incurred should one default on a mortgage, and so on. Second, the adjustment costs captured by our model likely vary across time and across people. New financial instruments can change the risk associated with making consumption commitments, as do changes in industry employment policies. This additional structure, provided by the more detailed modeling of the aversion to income shocks, generates testable implications that adding utility parameters does not.

\footnotetext{
${ }^{30}$ See Deaton [9] and Attanasio [2] for surveys of the habit formation literature.
} 
Imperfect wage insurance. The risk aversion induced by consumption commitments causes the workers in our model to prefer wages that do not fluctuate across states, a common implication of risk aversion (Azariadis [3], Baily [4], and Gordon [13]). In the absence of some constraint, the optimal labor market contract would ensure all risk, both wage and employment (Akerlof and Miyazaki [1]). A variety of market imperfections can give rise to optimal employment contracts that do not eliminate all risk, with this role in our model played by the assumption that wages cannot exceed marginal products. While firms may, in fact, be able to provide some insurance to workers by paying wages above marginal product temporarily, there are obvious limits to their ability to do this. ${ }^{31}$ The qualitative properties shown above - workers' preference for contracts that include layoffs and the possibility of multiple equilibria - are driven by the fact that workers cannot be completely insured.

Voluntary or involuntary unemployment? There is a long-standing debate in economics about whether unemployment is voluntary or involuntary. Lucas and Rapping [15] set out a model in which negative shocks may decrease marginal productivity to the point that workers prefer leisure time (or home production) to working at what would be the market wage. If this is the case, workers are voluntarily unemployed and unemployment is Pareto efficient; any policy aimed at reducing unemployment cannot be welfare-improving. Keynesians, on the other hand, argue that unemployment is involuntary, in the sense that unemployed workers would be willing to work at the prevailing wage (given their relevant attributes), but cannot find work. Unemployment in this sense typically leaves open the possibility of welfare-improving policies.

Taking the perspective of the model in this paper, the question of whether unemployment is voluntary or involuntary is more complicated. Workers accept a dynamic contract, knowing that under the contract, there is positive probability that they will be unemployed. That contract is the optimal feasible contract, given the constraints that prevent full insurance. Having accepted that contract, one might say that if a state of the world arises in which a worker finds himself unemployed, that unemployment is voluntary, since he voluntarily chose the contract from all feasible contracts. Rather than take this "ex ante viewpoint", however, one could take an interim

\footnotetext{
${ }^{31}$ Bewley [5, Table 13.1] states that of the reasons given by firms for laying off workers, over half gave financial distress, and nearly two thirds gave reduced sales. Our assumption is that a contract committing such a firm to maintaining employment would eventually be eroded by efforts on the part of the firm to reduce its labor force.
} 
viewpoint; at the time he finds himself unemployed, a worker would prefer to work at the wage paid those workers not laid off (or even less) to unemployment. It is not particularly fruitful to debate the proper notion of "voluntary"; the relevant question is whether a planner with the same information available to the firms and workers can improve on the contract. We assumed that firms could not perfectly insure the workers by continuing their employment at the same wage when subjected to negative productivity shocks. A planner who was constrained in the same way could not improve upon the contracts we analyze. If, however, the planner can provide the insurance, welfare improvements are possible. For example, the planner might provide loans to firms subjected to negative productivity shocks, enabling them to fully insure workers. While it is beyond the scope of this paper to investigate the plausibility of various such schemes, they would seem to give rise to serious incentive problems on the part of the firms.

Morale. Bewley [5, 6] discusses the tendency of employers to insure wage but not layoff risk. His suggestion is that wage reductions give rise to detrimental morale effects that do not accompany layoffs. This differential effect on morale is in turn traced to a convention that wage reductions, but not layoffs, are a violation of fairness or social norms. Our analysis suggests one reason why norms of behavior might arise that stress wage smoothing coupled with concentrated layoffs. If firms face constraints of the type in our model, profit maximization and worker choice may lead naturally to contracts of the type identified here: concentrated layoffs with wage stability for retained workers. If such contracts prevail over time and workers come to expect them, their optimal behavior will be such that they will bear large costs if firms behave otherwise; having made consumption commitments in anticipation of wage stability, they face large adjustment costs if their wages are reduced. And if the standard presumption is that such wage reductions do not occur, then a firm that flouts the convention by reducing wages may not only impose substantial economic hardship on its workers, but may destroy their morale as well.

We thus find nothing to disagree with in Bewley's suggestion that adverse morale effects may pose significant barriers to wage reductions. But why are wage reductions devastating for morale, reductions in overtime for hourly employees less so, and layoffs conducted within prescribed priority guidelines much less so? One possibility is that morale effects reinforce practices that are customary, with these practices having become customary because they are economically advantageous. 


\section{Appendix: Proofs}

Proof of Proposition 1. Let $\left(x_{1}, z\right)$ and $\left(x_{2}, z\right)$ be the optimal consumption bundles given wage profile $\left(w_{1}, w_{2}\right)$, so that

$$
\begin{aligned}
x & =\bar{w}-c_{C} z \\
& =p w_{1}+(1-p) w_{2}-c_{C} z \\
& =p x_{1}+(1-p) x_{2},
\end{aligned}
$$

using (5) for the second inequality and (3)-(4) for the third. Then we have

$$
\begin{aligned}
p U_{1}(\bar{w}, \bar{w})+(1-p) U_{2}(\bar{w}, \bar{w}) & \geq p U(x, z)+(1-p) U(x, z) \\
& =U(x, z) \\
& =U\left(p x_{1}+(1-p) x_{2}, z\right) \\
& >p U\left(x_{1}, z\right)+(1-p) U\left(x_{2}, z\right) \\
& =p U_{1}\left(w_{1}, w_{2}\right)+(1-p) U_{2}\left(w_{1}, w_{2}\right),
\end{aligned}
$$

where the first (weak) inequality holds because it is feasible to consume $(x, z)$ in both states given wage profile $(\bar{w}, \bar{w})$, and the second inequality holds because $U(x, z)$ is strictly concave in $x$ for fixed $z$. Eliminating the middle terms gives $(6)$.

Proof of Lemma 1. The first-order conditions for the consumer's utility maximization, attaching multipliers $\lambda_{1}$ and $\lambda_{2}$ to the two constraints, are given by ${ }^{32}$

$$
\begin{aligned}
p U_{x_{1}}^{\prime}\left(x_{1}, z\right)+\lambda_{1} & =0 \\
(1-p) U_{x_{2}}^{\prime}\left(x_{2}, z\right)+\lambda_{2} & =0 \\
p U_{z}^{\prime}\left(x_{1}, z\right)+(1-p) U_{z}^{\prime}\left(x_{2}, z\right)+\left(\lambda_{1}+\lambda_{2}\right) c_{C} & =0 .
\end{aligned}
$$

$>$ From the first two conditions, we have

$$
\frac{\lambda_{1}}{\lambda_{2}}=\frac{p U_{x_{1}}^{\prime}}{(1-p) U_{x_{2}}^{\prime}}
$$

However, we also have the constraints

$$
\begin{aligned}
& x_{1}=w_{1}-z c_{C} \\
& x_{2}=w_{2}-z c_{C} .
\end{aligned}
$$

If $w_{1}>w_{2}$, then these constraints give $x_{1}>x_{2}$ and hence $U_{x_{1}}^{\prime}<U_{x_{2}}^{\prime}$, which with (14) implies (7).

\footnotetext{
${ }^{32}$ Throughout, primes denote derivatives, with the subscript identifying the variable with respect to which the derivative is taken.
} 
Proof of Proposition 3. Attaching multiplier $\lambda$ to the constraint and multiplier $\beta$ to the participation constraint that $n_{1} \geq 0$ (one easily verifies that workers will not optimally be laid off in the good state), the first-order conditions are: ${ }^{33}$

$$
\begin{aligned}
& n_{1} \quad: p\left(f_{n_{1}}^{\prime}-w_{1}\right)-\lambda(1-p) \frac{n_{2}}{\left(n_{1}+n_{2}\right)^{2}} w_{2}+\beta=0 \\
& n_{2} \quad: \quad p\left(f_{n_{2}}^{\prime}-w_{1}\right)+(1-p)\left(g_{n_{2}}^{\prime}-w_{2}\right)+\lambda(1-p) \frac{n_{1}}{\left(n_{1}+n_{2}\right)^{2}} w_{2}=0(16) \\
& w_{1} \quad: \quad-p\left(n_{1}+n_{2}\right)+\lambda p=0 \\
& w_{2} \quad: \quad-(1-p) n_{2}+\lambda(1-p) \frac{n_{2}}{n_{1}+n_{2}}=0 .
\end{aligned}
$$

Assume that $n_{1}>0$, so that there are layoffs, and hence $\beta=0$. Coupling this with the equality $\lambda=n_{1}+n_{2}$, which we can derive from either of (17) or (18), we can rewrite (15)-(16) as

$$
\begin{aligned}
p\left(f_{n_{1}}^{\prime}-w_{1}\right)-(1-p) \frac{n_{2}}{n_{1}+n_{2}} w_{2} & =0 \\
p\left(f_{n_{2}}^{\prime}-w_{1}\right)+(1-p)\left(g_{n_{2}}^{\prime}-w_{2}\right)+(1-p) \frac{n_{1}}{n_{1}+n_{2}} w_{2} & =0 .
\end{aligned}
$$

Substituting the first of these into the second, we have

$$
(1-p) \frac{n_{2}}{n_{1}+n_{2}} w_{2}+(1-p)\left(g_{n_{2}}^{\prime}-w_{2}\right)+(1-p) \frac{n_{1}}{n_{1}+n_{2}} w_{2}=0,
$$

or

$$
g_{n_{2}}^{\prime}=0
$$

a contradiction. Hence, there must be no layoffs. Intuitively, this last condition indicates that layoffs will occur in the bad state only if the marginal product of labor in that state is zero. We can also conclude, from (16), that $w_{1}=f^{\prime}\left(n_{2}\right)$ and $w_{2}=g^{\prime}\left(n_{2}\right)$ which in turn implies that $w_{1}>w_{2}$.

Proof of Proposition 4. First, if both wages fall short of the corresponding marginal products, then the firm could increase profits by hiring more labor at the existing wage rate while preserving the existing probability of a layoff (and hence preserving worker utility). If $w_{1}$ equals its marginal product and $w_{2}$ falls short of its marginal product, then either $(1) w_{2}<w_{1}$, in

\footnotetext{
${ }^{33}$ Notice that the notation here is somewhat awkward, in that $f_{n_{1}}^{\prime}=f_{n_{2}}^{\prime}$ (since $f$ is a function of $n_{1}+n_{2}$ ), but seems a reasonable compromise between clutter and informativeness.
} 
which case the firm can increase $w_{2}$ and decrease $w_{1}$, preserving expected wage payments while increasing worker utility and leading to a state at which both wages fall short of their marginal products, at which point the firm can increase profits by hiring more labor; or (2) $w_{2} \geq w_{1}$, then there must be layoffs in the bad state and the firm can increase profits and consumer utility by hiring more labor in the bad state (and hence reducing the layoff probability). Hence, we must have $w_{2}=g^{\prime}$. If $w_{2}>w_{1}$, smoothing wages again increases consumer utility while preserving expected wage payments, allowing the firm to increase profits by increasing employment. Thus, we must have:

$$
f^{\prime} \geq w_{1} \geq w_{2}=g^{\prime}
$$

Attaching multipliers $\lambda$ and $\gamma$ to the constraints 9 and 10 and multiplier $\beta$ to the constraint $n_{1} \geq 0$, the first-order conditions for the firm's profit maximization problem are:

$$
\begin{aligned}
& n_{1}: p\left(f_{n_{1}}^{\prime}-w_{1}\right)-\lambda \frac{n_{2}}{\left(n_{1}+n_{2}\right)^{2}}\left(p U_{1}+(1-p) U_{2}\right) \\
& +\lambda p \frac{n_{2}}{\left(n_{1}+n_{2}\right)^{2}} w_{1}+\beta=0 \\
& n_{2}: p\left(f_{n_{2}}^{\prime}-w_{1}\right)+(1-p)\left(g_{n_{2}}^{\prime}-w_{2}\right)+\lambda \frac{n_{1}}{\left(n_{1}+n_{2}\right)^{2}}\left(p U_{1}+(1-p) U_{2}\right) \\
& -\lambda p \frac{n_{1}}{\left(n_{1}+n_{2}\right)^{2}} w_{1}+\gamma g_{n_{2} n_{2}}^{\prime \prime}=0
\end{aligned}
$$

Now suppose first that there are no layoffs, so that $n_{1}=0$. Then (21) becomes:

$$
p\left(f_{n_{2}}^{\prime}-w_{1}\right)+(1-p)\left(g_{n_{2}}^{\prime}-w_{2}\right)+\gamma g_{n_{2} n_{2}}^{\prime \prime}=0 .
$$

Now suppose that both wages equal marginal products. Then (24) can be satisfied only if $\gamma=0$. Using $\gamma=0$, we can write (22)-(23) as

$$
\begin{aligned}
-p n_{2}+\lambda\left(p \frac{d U_{1}}{d w_{1}}+(1-p) \frac{d U_{2}}{d w_{1}}\right) & =0 \\
-(1-p) n_{2}+\lambda\left(p \frac{d U_{1}}{d w_{2}}+(1-p) \frac{d U_{2}}{d w_{2}}\right) & =0,
\end{aligned}
$$


giving

$$
\frac{p}{1-p}=\frac{p \frac{d U_{1}}{d w_{1}}+(1-p) \frac{d U_{2}}{d w_{1}}}{p \frac{d U_{1}}{d w_{2}}+(1-p) \frac{d U_{2}}{d w_{2}}} .
$$

We now note that the terms in the numerator and denominator on the right side are the marginal (maximized) utilities of wages $w_{1}$ and $w_{2}$. A standard argument shows that these marginal utilities are equal to the multipliers $\lambda_{1}$ and $\lambda_{2}$ from the consumer's utility maximization problem with owned housing, giving

$$
\frac{p}{1-p}=\frac{\lambda_{1}}{\lambda_{2}}
$$

But this contradicts (7), given our assumption that there are no layoffs, and $w_{1}>w_{2}$ because workers are paid their marginal products). Hence, it must not be that both wages equal their respective marginal product. From (19), we then have $f^{\prime}>w_{1} \geq w_{2}=g^{\prime}$.

Now suppose that the optimal employment contract features layoffs in state 2. (It is straightforward to exclude the optimality of layoffs in state 1.) Suppose the first weak inequality in (19) an equality. Since $n_{1}>0$, we have $\beta=0$. From (20), we then have

$$
-\lambda \frac{n_{2}}{\left(n_{1}+n_{2}\right)^{2}}\left(p U_{1}+(1-p) U_{2}\right)+\lambda p \frac{n_{2}}{\left(n_{1}+n_{2}\right)^{2}} w_{1}=0 .
$$

As a result, we have

$$
p w_{1}=p U_{1}+(1-p) U_{2} .
$$

This is a contradiction. The maximum utility achieved when renting housing and faced with wages $w_{1}$ in state 1 and 0 in state 2 is $p w_{1}$. A consumer who has income $w_{2}>0$ in state 2 and rents must then receive a higher utility, and a consumer with income $w_{2}$ who chooses to own housing must receive a utility at least as high as the latter, giving the contradiction. Hence, we must have $f^{\prime}>w_{1} \geq w_{2}=g^{\prime}$.

Proof of Proposition 5. We assume that the optimal contract features no layoffs and seek a contradiction. Because consumption is entirely committed, the optimal no-layoff contract must feature $n^{*}=n_{2}, n_{1}=0$, and $w_{1}=w_{2}=g^{\prime}\left(n_{2}\right)$. Beginning with this contract, consider an adjustment that decreases $n_{2}$, increases $w_{1}=w_{2} \equiv w$ so as to preserve the equality of the state- 2 wage and the marginal product of labor (i.e., $d w / d n_{2}=g^{\prime \prime}\left(n_{2}\right)$ ), and increases $n_{1}$ so as to preserve the firm's expected profits. It is a contradiction to show that this adjustment increases consumer utility. 
The firm's profits from the putative equilibrium contract are

$$
p\left[f\left(n_{1}+n_{2}\right)-w\left(n_{1}+n_{2}\right)\right]+(1-p)\left[g\left(n_{2}\right)-w n_{2}\right],
$$

where the assumption that there are no layoffs gives $n_{1}=0$. We now take a derivative with respect to $n_{2}$, adjusting $w$ so as to preserve equality with the marginal product of labor in the bad state and adjusting $n_{1}$ so as to preserve expected profits, giving:

$p\left(f^{\prime}\left(n_{1}+n_{2}\right)-w\right)\left[\frac{d n_{1}}{d n_{2}}+1\right]+(1-p)\left[g^{\prime}\left(n_{2}\right)-w\right]-p \frac{d w}{d n_{2}}\left(n_{1}+n_{2}\right)-(1-p) \frac{d w}{d n_{2}} n_{2}=0$.

Because $g^{\prime}\left(n_{2}\right)=w, d w / d n_{2}=g^{\prime \prime}\left(n_{2}\right)$, and $n_{1}=0$ by assumption, we can rearrange to obtain

$$
\frac{d n_{1}}{d n_{2}}=-\frac{p\left[f^{\prime}\left(n_{2}\right)-g^{\prime}\left(n_{2}\right)\right]-g^{\prime \prime}\left(n_{2}\right) n_{2}}{p\left[f^{\prime}\left(n_{2}\right)-g^{\prime}\left(n_{2}\right)\right]} .
$$

The consumer's utility, given that housing is owned, is given by

$$
\frac{n_{2}}{n_{1}+n_{2}} k w+\frac{n_{1}}{n_{1}+n_{2}} p w .
$$

Differentiating gives:

$\frac{d w}{d n_{2}}\left[\frac{k n_{2}+p n_{1}}{n_{1}+n_{2}}\right]+w\left(k \frac{n_{1}+n_{2}-n_{2}\left(\frac{d n_{1}}{d n_{2}}+1\right)}{\left(n_{1}+n_{2}\right)^{2}}+p \frac{\frac{d n_{1}}{d n_{2}}\left(n_{1}+n_{2}\right)-n_{1}\left(\frac{d n_{1}}{d n_{2}}+1\right)}{\left(n_{1}+n_{2}\right)^{2}}\right)$.

Using the facts that $w=g^{\prime}\left(n_{2}\right), n_{1}=0$ and $d w / d n_{2}=g^{\prime \prime}\left(n_{2}\right)$, we have a contradiction if

$$
g^{\prime \prime}\left(n_{2}\right) k n_{2}<g^{\prime}\left(n_{2}\right)(k-p) \frac{d n_{1}}{d n_{2}}
$$

or

$$
-\theta k<(k-p) \frac{d n_{1}}{d n_{2}}
$$

Using (27), this is

$$
p\left(f^{\prime}\left(n_{2}\right)-g^{\prime}\left(n_{2}\right)\right) \theta k>(k-p)\left(p\left(f^{\prime}\left(n_{2}\right)-g^{\prime}\left(n_{2}\right)\right)-g^{\prime \prime}\left(n_{2}\right) n_{2}\right),
$$

or, using the fact that $f^{\prime}\left(n_{2}\right)-g^{\prime}\left(n_{2}\right)=(\alpha-1) g^{\prime}\left(n_{2}\right)$,

$$
p(\alpha-1) \theta k>(k-p)(p(\alpha-1)+\theta) .
$$


Proof of Proposition 6. [STEP 1] We begin by collecting some preliminary observations. First, given that $g(n)=\ln n$, we have

$$
\theta(n)=-\frac{n g^{\prime \prime}(n)}{g^{\prime}(n)}=1
$$

The important feature here is that this elasticity is constant, simplifying the calculations, which do not depend upon its particular value. We will find it convenient to denote the ratio $\frac{n_{1}}{n_{2}}$ by $N$.

Second, because $f(n)=\alpha g(n)$, we have

$$
f^{\prime}\left(n_{1}+n_{2}\right)=\alpha g^{\prime}\left(n_{1}+n_{2}\right)=\frac{\alpha}{n_{1}+n_{2}}=\frac{\alpha}{n_{2}(1+N)}=\frac{\alpha}{1+N} g^{\prime}\left(n_{2}\right) .
$$

We now write the firm's profit maximization problem solely as a function of $n_{2}$, recognizing that in equilibrium the firm will pay the same wage in both states (because consumption is fully vulnerable to risk), where this wage will be given by $g^{\prime}\left(n_{2}\right)$, and that $n_{1}$ will be given by a function $n_{1}\left(n_{2}\right)$ that causes the consumer's participation constraint to hold with equality. The consumer's participation constraint is given by

$$
\frac{n_{2}}{n_{1}+n_{2}} k w+\frac{n_{1}}{n_{1}+n_{2}} p w \geq \bar{U}
$$

Hence, for $\bar{n}_{2}$ with $k g^{\prime}\left(\bar{n}_{2}\right)=\bar{U}$, we have $n_{1}=0$. This is the optimal contract without layoffs. The firm will never find it optimal to hire more than $\bar{n}_{2}$ workers in state 2 . As $n_{2}$ declines, the wage $g^{\prime}\left(n_{2}\right)$ increases, and in response, so does $n_{1}$ and hence the unemployment risk. The firm's profits are then given by

$$
\pi\left(n_{2}\right)=p\left[f\left(n_{2}+n_{1}\left(n_{2}\right)\right)-g^{\prime}\left(n_{2}\right)\left(n_{2}+n_{1}\left(n_{2}\right)\right)\right]+(1-p)\left[g\left(n_{2}\right)-g^{\prime}\left(n_{2}\right) n_{2}\right] .
$$

Differentiating gives, suppressing the arguments of some functions,

$$
\begin{aligned}
\frac{d \pi\left(d n_{2}\right)}{d n_{2}} & =p\left[f^{\prime}-g^{\prime}\right]\left(\frac{d n_{1}}{d n_{2}}+1\right)+(1-p)\left[g^{\prime}-g^{\prime}\right]-g^{\prime \prime}\left[n_{2}+p n_{1}\right] \\
& =p\left[\frac{\alpha}{1+N}-1\right] g^{\prime}\left(\frac{d n_{1}}{d n_{2}}+1\right)-g^{\prime \prime} n_{2}[1+p N]
\end{aligned}
$$

Hence, we have a first-order condition (for interior solutions) of

$$
\frac{1}{g^{\prime}} \frac{d \pi\left(n_{2}\right)}{d n_{2}}=p\left[\frac{\alpha}{1+N}-1\right]\left(\frac{d n_{1}}{d n_{2}}+1\right)+\theta[1+p N]=0 .
$$


The second term on the right side is positive, and hence in equilibrium the first must be negative, which is consistent with $d n_{1} / d n_{2}<0$.

[STEP 2] Now suppose that $p$ is replaced by a new, higher probability $p^{\prime}$, making the good state more likely. It suffices to argue that the resulting adjustments increase the value $n_{1} / n_{2}$.

If $n_{1}, n_{2}, w$ and (counterfactually) $d n_{1} / d n_{2}$ remain unchanged, then the firm's first-order condition is now negative. (The first-order condition was zero at price $p$, and the increase to $p^{\prime}$ increases proportionately every term in the first-order condition except $\theta$, which is positive and remains unchanged, so the condition must now be negative). However, the consumer has also been pushed above the participation constraint, now finding the employment contract strictly better than the alternative. The negative firm derivative is thus not informative, since we no longer satisfy the constraints supposedly built into this derivative. Let us then consider the following adjustment. The ratio $N=\frac{n_{1}}{n_{2}}$ is held constant while $n_{2}$ is increased and $w$ decreased (to satisfy $w=g^{\prime}\left(n_{2}\right)$ ) until a value $n_{2}^{\prime}$ is reached at which the consumer's participation constraint binds. Since we can rewrite (28) as

$$
\frac{1}{1+N} k w+\frac{N}{1+N} p w \geq \bar{U}
$$

there must be a value of $n_{2}^{\prime}$ which induces a value of $w$ (given the fixed $N)$ at which this binds. At this point, the consumer's participation constraint is satisfied with equality and hence the firm's first-order condition is informative.

We now argue that this increase of $n_{2}$ to $n_{2}^{\prime}$, while holding fixed $n_{1} / n_{2}$ and (hypothetically) $d n_{1} / d n_{2}$, preserves the negative value of the right side of $(29)$ (evaluated at $p^{\prime}$ ). We have seen that the right side is negative when evaluated at $p^{\prime}$, before the increase in $n_{2}$. Since $N$ has been held constant while increasing $n_{2}$ to $n_{2}^{\prime}$, it suffices to show that the combination of an increase from $p$ to $p^{\prime}$ and from $n_{2}$ to $n_{2}^{\prime}$ has decreased (increased the absolute value, since $\left.d n_{1} / d n_{2}<0\right)$ the term $d n_{1} / d n_{2}$. We implicitly differentiate the consumer's participation constraint to find this derivative:

$$
\begin{aligned}
0 & =\frac{n_{1}+n_{2}-n_{2}\left(\frac{d n_{1}}{d n_{2}}+1\right)}{\left(n_{1}+n_{2}\right)^{2}} k w+\frac{\frac{d n_{1}}{d n_{2}}\left(n_{1}+n_{2}\right)-n_{1}\left(\frac{d n_{1}}{d n_{2}}+1\right)}{\left(n_{1}+n_{2}\right)^{2}} p w+\frac{k n_{2}+p n_{1}}{n_{1}+n_{2}} \frac{d w}{d n_{2}} \\
& =\frac{n_{1}-n_{2} \frac{d n_{1}}{d n_{2}}}{n_{1}+n_{2}} k g^{\prime}+n_{2} \frac{\frac{d n_{1}}{d n_{2}} n_{2}-n_{1}}{n_{1}+n_{2}} p g^{\prime}+\left(k n_{2}+p n_{2}\right) g^{\prime \prime} \\
& =\frac{n_{1}}{n_{1}+n_{2}}(k-p) g^{\prime}+\frac{d n_{1}}{d n_{2}} \frac{p-k}{n_{1}+n_{2}} g^{\prime}+\left(k n_{2}+p n_{1}\right) g^{\prime \prime} .
\end{aligned}
$$


We can then solve for

$$
\begin{aligned}
\frac{d n_{1}}{d n_{2}} & =\left(\frac{n_{1}(k-p)}{n_{1}+n_{2}}+\left(k n_{2}+p n_{1}\right) \frac{g^{\prime \prime}}{g^{\prime}}\right) \frac{n_{1}+n_{2}}{k-p} \frac{1}{n_{2}} \\
& =\frac{n_{1}}{n_{2}}+\frac{\left(k n_{2}+p n_{1}\right)\left(n_{1}+n_{2}\right)}{k-p} \frac{1}{n_{2}} \frac{g^{\prime \prime}}{g^{\prime}} \\
& =\frac{n_{1}}{n_{2}}-\theta \frac{\left(k+p \frac{n_{1}}{n_{2}}\right)\left(1+\frac{n_{1}}{n_{2}}\right)}{k-p} \\
& =N-\theta \frac{(k+p N)(1+N)}{k-p}<0,
\end{aligned}
$$

where we can infer the inequality from the firm's first-order condition.

We now see that the increase from $n_{2}$ to $n_{2}^{\prime}$ has no effect on $d n_{1} / d n_{2}$, given that $N$ is held fixed. An individual worker cares only about her wage and layoff probability, not the aggregate amount of labor hired. The increase from $p$ to $p^{\prime}$ increases the absolute value of the second term, which enters with a negative sign, and hence $d n_{1} / d n_{2}$ becomes smaller.

[STEP 3] We have shown that increasing the probability of a good state from $p$ to $p^{\prime}$, while holding the layoff risk constant and adjusting the wage and total employment to preserve the participation constraint, yields a situation in which $d \pi_{2}\left(n_{2}^{\prime}\right) / d n_{2}<0$. The firm's profits are thus increasing as $n_{2}$ decreases (and $w$ increases, to preserve equality with the marginal product of labor, and so $n_{1} / n_{2}$ increases, to preserve the participation constraint). This establishes the result, if we can verify that the firm's profit maximization problem is sufficiently well behaved, meaning that a negative value of $d \pi\left(n_{2}^{\prime}\right) / d n_{2}$ ensures that the profit maximizing value of $n_{2}$ is indeed lower than $n_{2}^{\prime}$. For this, we must return to the firm's first-order condition. Substituting for $d n_{1} / d n_{2}$, we can write this as:

$$
\begin{aligned}
& \frac{d \pi\left(n_{2}\right)}{d n_{2}}=p\left(\frac{\alpha}{1+N}-1\right)\left((1+N)-\theta \frac{(k+p N)(1+N)}{k-p}\right)+\theta(1+p N) \\
& =p\left(\alpha-\alpha \theta \frac{k+p N}{k-p}-(1+N)+\theta \frac{(k+p N)(1+N)}{k-p}\right)+\theta(1+p N) .
\end{aligned}
$$

Viewed as a function of $N$, this expression is quadratic, becoming arbitrarily large as $N$ becomes either arbitrarily small or arbitrarily large. It is straightforward to verify that the function is positive at $N=-1$. Noting that only positive values of $N$ are relevant, and that $N$ and $n_{2}$ are inversely related, we then have two possibilities. First, the function $\pi\left(n_{2}\right)$ may have 
only one interior extreme point on $\left[0, \bar{n}_{2}\right]$, which is a maximum. (This case obtains if (30) is negative when $N=0$.) In this case, finding $d \pi\left(n_{2}^{\prime}\right) / n_{2}<0$ suffices to conclude that the optimal value of $n_{2}$ lies below $n_{2}^{\prime}$. Second, there may be two interior extreme points, with $d \pi\left(\bar{n}_{2}\right) / d n_{2}>0$ and with the interior maximum at a value of $n_{2}$ less than $n_{2}^{\prime}$. (This case obtains if (30) is positive when $N=0$.) In this case, it remains only to argue that the interior maximum dominates the boundary maximum at $\bar{n}_{2}$. However, for the original value of $p$, our assumption was that the optimal contract involved layoffs. If this layoff contract dominates the no-layoff contract for probability $p$, then it must also do so for probability $p^{\prime}$. This ensures that the interior maximum, corresponding to an optimal contract with layoffs, dominates the no-layoff boundary maximum at $\bar{n}_{2}$.

\section{References}

[1] George A. Akerlof and Hajime Miyazaki. The implicit contract theory of unemployment meets the wage bill argument. Review of Economic Studies, 67:321-338, 1980.

[2] Oratzio Attanasio. Consumption. In John Taylor and Michael Woodford, editors, Handbook of Macroeconomics, chapter 11, pages 741-812. Amsterdam: Elsevier, 1999.

[3] Costas Azariadis. Implicit contracts and underemployment equilibria. Journal of Political Economy, 83:1183-1202, 1975.

[4] Martin Neil Baily. Wages and unemployment under uncertain demand. Review of Economic Studies, 41:37-50, 1974.

[5] Truman F. Bewley. Why Wages Don't Fall During a Recession. Harvard University Press, Cambridge, Massachusetts, 1999.

[6] Truman F. Bewley. Fairness, reciprocity and wage rigidity. Discussion paper no. 1383, Cowles Foundation for Research in Economics at Yale University, 2002.

[7] Raj Chetty. Consumption commitments, unemployment durations, and local risk aversion. Technical report, Harvard University, 2002.

[8] Raj Chetty and Adam Szeidl. Consumption Commitments and Asset Prices. Technical report, Harvard University, 2004. 
[9] Angus Deaton. Understanding Consumption. Clarendon Press, Oxford, 1992.

[10] Tore Ellingsen and Steinar Holden. Sticky Consumption and Rigid Wages. In Market Behavior and macroeconomic Modelling, eds. Steven Brakman, Hans van Ees, and Simon K. Kuipers, Basingstoke: Macmillan, 1998.

[11] Tore Ellingsen and Steinar Holden. A Durable Relationship. Mimeo, Department of Economics, Stockholm School of Economics, 2002.

[12] Price V. Fishback, William C. Horrace, and Shawn Kantor. The origins of modern housing finance: The impact of federal housing programs during the great depression. Mimeo, University of Arizona, 2001.

[13] Donald F. Gordon. A neoclassical theory of Keynesian unemployment. Economic Inquiry, 12:431-459, 1974.

[14] Richard E. Kihlstrom and Leonard J. Mirman. Constant, increasing and decreasing risk aversion with many commodities. Review of Economic Studies, 68:271-280, 1981.

[15] Robert E. Lucas and Leonard A. Rapping. Real wages, employment and inflation. Journal of Political Economy, 77:721-754, 1969. 